\title{
Fragment ion-functional group relationships in organic aerosols using aerosol mass spectrometry and mid-infrared spectroscopy
}

\author{
Amir Yazdani ${ }^{1}$, Nikunj Dudani ${ }^{1}$, Satoshi Takahama ${ }^{1}$, Amelie Bertrand ${ }^{2}$, André S. H. Prévôt ${ }^{2}$, Imad El \\ Haddad $^{2}$, and Ann M. Dillner ${ }^{3}$ \\ ${ }^{1}$ ENAC/IIE Swiss Federal Institute of Technology Lausanne (EPFL), 1015 Lausanne, Switzerland \\ ${ }^{2}$ Laboratory of Atmospheric Chemistry, Paul Scherrer Institute, 5232 Villigen, Switzerland \\ ${ }^{3}$ Air Quality Research Center, University of California Davis, Davis, California, USA
}

Correspondence: Satoshi Takahama (satoshi.takahama@epfl.ch) and Imad El Haddad (imad.el-haddad@psi.ch)

\begin{abstract}
.
Aerosol mass spectrometry (AMS) and mid-infrared spectroscopy (MIR) are two analytical methods for characterizing the chemical composition of OM. While AMS provides high-temporal-resolution bulk measurements, the extensive fragmentation during the electron impact (EI) ionization makes the characterization of OM components limited. The analysis of aerosols collected on PTFE filters using MIR, on the other hand, provides functional group (FG) information with reduced sample alteration but results in a relatively low temporal resolution. In this work, we compared and combined MIR and AMS measurements for several environmental chamber experiments to achieve a better understanding of the AMS spectra and the OM chemical evolution by aging. Fresh emissions of wood and coal burning were injected into an environmental simulation chamber and aged with hydroxyl and nitrate radicals. A high-resolution time-of-flight (HR-TOF) AMS measured the bulk chemical composition of fine PM. Fine aerosols were also sampled on PTFE filters before and after aging for the offline MIR analysis. After comparing AMS and MIR bulk measurements, we used multivariate statistics to identify the influential functional groups contributing to AMS OM mass for different aerosol sources and aging processes. We also identified the key mass fragments resulting from each functional group for the complex OM generated from biomass and fossil fuel combustion. Finally, we developed a statistical model that enables estimation of the high-time-resolution functional group composition of OM using collocated AMS and MIR measurements. Using this approach, AMS spectra can be used to interpolate the functional group measurements by MIR, allowing us to better understand the evolution of OM during the aging process.
\end{abstract}

\section{Introduction}

Particulate matter (PM) impacts visibility, climate, and human health (Hallquist et al., 2009). Organic matter (OM), which accounts for an important fraction of total fine atmospheric PM mass, has profound effects on aerosol-related phenomena (Turpin and Lim, 2001; Russell, 2003; Shiraiwa et al., 2017). Characterizing the organic fraction is necessary to reduce the 
uncertainties associated with the impact of PM and can in turn affect the policies related to climate change and air quality management (Zhang et al., 2011; Turpin and Lim, 2001). However, OM chemical composition and formation mechanisms have not yet been fully understood due to their complexity.

Different analytical and computational techniques exist for determination of the chemical composition of organic aerosols (OAs) and especially secondary organic aerosols (SOAs). Modeling all important SOA-related reaction and species is not feasible for large-scale models (Jathar et al., 2015) and simpler models often do not reproduce the measured concentrations and dynamics of SOA evolution in polluted regions (Volkamer et al., 2006). Among the analytical techniques, aerosol mass spectrometry (AMS) and mid-infrared (MIR) spectroscopy are able to provide bulk chemical information for most of OM mass (Hallquist et al., 2009).

AMS provides information about the chemical composition of $\mathrm{OM}$ and its temporal variations in terms of ensemble mass spectra acquired over short time intervals (Zhang et al., 2011). Aerodyne Research aerosol mass spectrometer (used in this work and referred to as "AMS") is the most widely used thermal desorption-based mass spectrometers in aerosol research. AMS is capable of quantifying non-refractory species (e.g., sulfate, nitrate, ammonium, chloride, and $\mathrm{OM}$ ) by thermal vaporization (typically at $600^{\circ} \mathrm{C}$ ) and electron impact ionization (EI; typically at $70 \mathrm{eV}$ ) (Canagaratna et al., 2007). In spite of the valuable information that AMS provides, the AMS OM fragment ions are not molecule-specific and are difficult to interpret due to the extensive fragmentation of molecules with the high-energy electron impact (EI) ionization and flash vaporization. This limits the level of molecular details that can be extracted from the AMS mass spectra (Canagaratna et al., 2007; Kumar et al., 2018; Faber et al., 2017; Chhabra et al., 2011a). Organic aerosol components can also undergo oxidation, dehydration and/or decarboxylation reactions inside the AMS ionization chamber (Canagaratna et al., 2015a). In addition, uncertainties regarding the relative ionization efficiency (Xu et al., 2018), fragmentation tables (Aiken et al., 2008), gas-phase interference (Canagaratna et al., 2015a), and collection efficiency (Frossard et al., 2014) have been reported. There are soft ionization methods, such as electrospray ionization (ESI) and chemical ionization (CI) that minimize the analyte fragmentation at the expense of variable ionization efficiency, signal-to-noise ratio, and quantifying bulk OM composition (Lopez-Hilfiker et al., 2019; Nozière et al., 2015; Iyer et al., 2016; Zahardis et al., 2011).

MIR spectroscopy, which is commonly performed off-line on polytetrafluoroethylene (PTFE) filters (Takahama et al., 2013; Ruthenburg et al., 2014), is used as a complementary method to AMS in this work. This non-destructive method gives direct functional group (FG) information; provides measurements consistent with commonly used instruments in monitoring networks (Boris et al., 2019); and is capable of differentiating between the composition of different oxidized OMs. For example, Liu et al. (2012) observed very similar AMS mass spectra for several SOA samples, while the complementary MIR spectra indicated clear chemical differences for these aerosols. In addition to FG quantification, MIR spectroscopy has been recently used to quantify biomass burning markers in the atmospheric aerosols (e.g., levoglucosan and lignin; Yazdani et al., 2020b). However, MIR spectroscopy on filters has low temporal resolution compared to on-line instruments such as AMS (Faber et al., 2017; Yazdani et al., 2020b). Moreover, volatilization of volatile organic compounds from PTFE filters during or after sampling can affect OM mass and composition (Subramanian et al., 2004). Uncertainties regarding variable absorptivities by different 
organic molceules (Hastings et al., 1952), peak overlaps (Pavia et al., 2008), scattering, and PTFE interference (Takahama et al., 2013) have also been reported for this technique.

Past studies compared AMS and MIR OM, O:C, and positive matrix factorization (PMF) factors in field campaigns (Gilardoni et al., 2009; Russell et al., 2009b; Frossard et al., 2011; Liu et al., 2011; Corrigan et al., 2013; Frossard et al., 2014), reporting reasonable agreement between the instruments despite the aforementioned uncertainties. Two controlled laboratory studies tried to understand the relationship between fragment ions and functional groups (Faber et al., 2017; Russell et al., 2009a) using univariate correlations. In this work, we compare and combine the AMS and MIR measurements for the organic aerosols of moderate to high complexity from biomass burning and coal combustion emissions, two major sources of atmospheric OM, in an environmental chamber. We apply additional uni- and multivariate techniques to further interpret the relationships between more than 300 AMS fragment ions and 4 MIR FGs, and provide a method to predict the high-timeresolution evolution of FGs using AMS.

\section{Methods}

In the following sections, the experimental set-up (Sect. 2.1), on-line and off-line measurement techniques (Sects. 2.2 and 2.3) are described. Thereafter, statistical methods used for combining AMS and MIR measurements are explained (Sects. 2.4-2.6). The experimental set-up, procedure, and data used in this work are the same as those reported by Yazdani et al. (2020b).

\subsection{Laboratory experimental set-up and procedure}

Briefly, we conducted four wood burning (WB) experiments with beech wood logs and five coal combustion (CC) experiments with bituminous coal using ordinary modern stoves (Bruns et al., 2015). The emissions were diluted and then injected into a $6 \mathrm{~m}^{3}$ Teflon bag environmental chamber of at the Paul Scherrer Institute (PSI) in Villigen, Switzerland. The injections were continued until the concentration of PM and OM measured by the scanning mobility particle sizer (SMPS) and high-resolution time-of-flight (HR-ToF) AMS reached atmospherically-relevant values. The emissions were held in the chamber for 30 minutes after injection to improve mixing. Thereafter, primary emissions were chemically aged using the hydroxyl or nitrate radical in order to simulate daytime and nighttime aging mechanisms, respectively. For the diurnal aging simulations, the $\mathrm{OH}$ radical was produced by the photolysis of $\mathrm{HONO}$ and the $\mathrm{OH}$ exposures reached (2-3) $\times 10^{7} \mathrm{molec}^{-3} \mathrm{~h}$ (measured using butanol-d9; Barmet et al., 2012) corresponding to 20-30 hours of aging in the atmosphere. For the nocturnal aging experiments, the $\mathrm{NO}_{3}$ radical was produced by a single injection of $\mathrm{O}_{3}$ and $\mathrm{NO}_{2}$ in the chamber. The nitrate radical concentration was estimated to be (1.5-2.5) $\times 10^{7}$ molec $\mathrm{cm}^{-3}$ for the first hour of aging process based on the phenol concentration decay in the gas phase.

\subsection{Online AMS PM measurements}

Non-refractory particle composition was measured with a HR-ToF AMS operating in V mode (mass resolution $\Delta m / m=2100$ for $\mathrm{m} / \mathrm{z}$ 200; DeCarlo et al., 2006) with a $2.5 \mu \mathrm{m}$ inlet aerodynamic lens throughout the experiment. The raw signal was postprocessed in Igor Pro 6.3 (Wave Metrics) using SQUIRREL 1.57 and PIKA 1.15Z routines. Elemental ratios of OM were 
estimated following the approach of Canagaratna et al. (2015a) (Fig. S1). The AMS OM concentrations reported in this work are not corrected for the chamber wall losses and the measured nitrate is assumed to be inorganic for ease of comparison with MIR.

\subsection{Offline MIR PM measurements}

Two $47 \mathrm{~mm}$ Teflon filters (Pall corporation) were used for each experiment to sample the primary PM after its injection into the chamber and the aged PM after approximately three to four hours of aging. The filter holder was placed downstream of a sharp-cut-off cyclone and a silica gel denuder and the flow rate through the filter was maintained at $8 \mathrm{~L} \mathrm{~min}^{-1}$. We used a similar naming convention for the filters to that of Yazdani et al. (2020b). Filters were immediately stored in filter petri dishes at $253 \mathrm{~K}$ after sampling and before MIR analysis to minimize volatilization and chemical reactions. The PTFE filters were analyzed using a Bruker Vertex 80 Fourier transform infrared (FT-IR) instrument equipped with an $\alpha$ deuterated lanthanum alanine doped triglycine sulfate (DLaTGS) detector, at a resolution of $4 \mathrm{~cm}^{-1}$. The spectra were averaged over 64 scans.

\subsubsection{MIR Spectral postprocessing}

The MIR spectra were baseline-corrected to eliminate the contribution of light scattering by filter membrane and particles as well as absorption by graphitic carbon (Parks et al., 2021). We used a smoothing spline described by Kuzmiakova et al. (2016). After baseline correction, the scaled and baseline-corrected spectrum of a blank filter was subtracted from the baselinecorrected sample spectra to minimized the interference of PTFE C-F bands. After baseline correction and blank subtraction, the multiple peak-fitting algorithm described by Takahama et al. (2013) was applied on the spectra to obtain FG abundances of alcohol $(\mathrm{aCOH})$, carboxylic acid $(\mathrm{COOH})$, alkane $(\mathrm{aCH})$, non-acid carbonyl (naCO) (Supplement Fig. S1). After obtaining FG abundances, the O:C, H:C, and OM:OC ratios (Fig. S1) were calculated assuming $0.5 \mathrm{C}$ atom for each of aCH and aCOH bonds (Chhabra et al., 2011b; Russell, 2003; Maria et al., 2002).

\subsection{Identifying influential MIR absorbances for AMS OM}

The AMS OM estimates and the MIR spectra are combined statistically to identify the functional groups that influence the former OM mass concentration the most. The results of this method, which are affected neither by uncertainties of MIR peak fitting nor by absorption coefficients, identify important predictors of OM estimated by more routinely applied methods prior to peak fitting. This technique can be applied even when absorption coefficient data are not available for all FGs, and help decide which FGs are needed to be included in the MIR peak fitting. The averaged AMS OM concentrations over the filter sampling periods were regressed against the corresponding MIR spectra using partial least squares regression (PLSR). Thereafter, the influential absorbances in the MIR spectra for the organic OM concentration were determined based on variable importance in projection (VIP) scores of the PLSR model (Fig. S2). This procedure was applied separately for the primary and aged aerosols of each source to highlight the compositional differences. By regressing AMS OM concentration against MIR absorbances, we 
seek a solution of the following linear equation for coefficients $a$ :

$\boldsymbol{y}=\mathrm{X} \boldsymbol{a}+\boldsymbol{e}$

where $\mathbf{X}(n \times p)$ is the MIR spectra matrix with $n$ samples and $p$ independent variable (wavenumbers), $\boldsymbol{y}(n \times 1)$ is the vector of response variable, AMS OM concentration, and $e$ is the vector of residuals. In this work, the univariate partial least squares regression (Wold et al., 1983) is used. The univariate PLSR projects $\mathbf{X}$ onto $\mathbf{P}(p \times h)$ ( $h$ is the number of latent variables) basis with orthogonal scores $\mathbf{T}(n \times h)$, while maximizing the covariance between scores and the response variable, $\boldsymbol{y}$. In Eq. (3), $\boldsymbol{b}$ and $\boldsymbol{f}$ indicate the regression coefficients the vector of residuals, respectively.

$$
\begin{array}{r}
\mathbf{X}=\mathbf{T} \mathbf{P}^{\top}+\mathbf{E}, \\
y=\mathbf{T} \boldsymbol{b}+\boldsymbol{f} .
\end{array}
$$

After solving the regression equation using PLSR for different number of latent variable (LVs), a repeated 10-fold cross validation was applied to find the optimal number of latent variables and avoid under/overfitting. Examining loadings and coefficients directly can be informative about the important absorbances. For instance, the first weight vector, $\boldsymbol{w}_{1}$, can be a good estimate of important bands but it is limited to the cases that signal is not dominated by other factors rather than the analyte, such as inorganics, and filter absorption (Haaland and Thomas, 1988). In this work, we used a more general method, VIP scores (Wold et al., 1993), to identify the important absorption bands. This metric is a root mean square of loading weights of all $h$ latent variables used in the model weighted by their fraction of the captured response (Chong and Jun, 2005; Takahama et al., 2016). The VIP score of the $j$ th wavenumber is calculated by considering all $h$ latent variables in the model as shown in Eq. (4). Since the average of squared VIP scores is equal to one, generally, the wavenumbers with VIP score greater than one are considered influential due to higher-than-average contribution to estimating the response variable. In Eq. (4), $\boldsymbol{t}_{k}$ and $\boldsymbol{w}_{k}$ represent the $k$ th columns of $\mathbf{T}$, score matrix, and $\mathbf{W}(p \times h)$, weight matrix, respectively and the relationship between $\mathbf{T}$ and W is described by Eq. (5) (Helland, 1988).

$\boldsymbol{V} \boldsymbol{I} \boldsymbol{P}_{j}=\sqrt{p \frac{\sum_{k=1}^{h} S S\left(b_{k} \boldsymbol{t}_{k}\right)\left(\boldsymbol{w}_{j k} /\left\|\boldsymbol{w}_{k}\right\|\right)^{2}}{\sum_{k=1}^{h} S S\left(b_{k} \boldsymbol{t}_{k}\right)}}$,

$\mathbf{T}=\mathbf{X W}\left(\mathbf{P}^{\top} \mathbf{W}\right)^{-\mathbf{1}}$

\subsection{Identifying FG-ion fragment relationships}

Covariance and correlation coefficients were used to understand the connection between fragment ions (up to $\mathrm{m} / \mathrm{z} 202$ for which

the signal-to-noise ratios are still significant) and FGs (Fig. S3a). We used normalized functional group abundances by MIR total OM and normalized fragment ion concentrations by AMS total OM (averaged over filter sampling periods) and calculated 
covariances and correlations between 4 FGs and more than 300 fragment ions. The major difference between the fragmentFG correlation and covariance is that the former is more informative about the fragments with low concentrations while the latter highlights the fragments with higher concentrations. Data normalization was performed to avoid correlations introduced by the changes in the total OM mass concentration as oxygenated fragments are highly correlated before normalization (Fig. S5). In addition, negative correlations (anti-correlations) and covariances were omitted as they do not show the production of fragments by FGs. For example, often the aCH relative abundance decreases with aging as the relative concentrations of oxygenated FGs such as $\mathrm{COOH}$ and oxygenated fragment ions such as $\mathrm{CO}_{2}{ }^{+}$increase, leading to a significant anti-correlation between the aCH FG and the $\mathrm{CO}_{2}{ }^{+}$fragment. Russell et al. (2009a) and Faber et al. (2017) have already applied the univariate fragment-FG (correlation) analysis for different sources using unit-mass-resolution and HR AMS data, respectively. However, their analysis has been limited to only a few light fragment ions.

Univariate methods can be difficult to interpret when ion fragments are produced by multiple functional groups. Therefore, in addition to the univariate methods, the VIP scores method was used to highlight the influential spectral regions and FGs for major fragment ions with high concentrations $\left(\mathrm{CO}_{2}^{+}, \mathrm{CHO}^{+}, \mathrm{C}_{2} \mathrm{H}_{3} \mathrm{O}^{+}, \mathrm{C}_{3} \mathrm{H}_{5}^{+}\right)$and for two biomass-burning-related fragment ions $\left(\mathrm{C}_{2} \mathrm{H}_{4} \mathrm{O}_{2}{ }^{+}\right.$for levoglucosan and $\mathrm{C}_{8} \mathrm{H}_{9} \mathrm{O}_{2}{ }^{+}$for lignin). This multivariate approach, which is not affected by the MIR peak fitting uncertainties, is similar to identifying the influential MIR spectral regions for the AMS OM as discussed in Sect. 2.4 except that the concentrations of individual fragment ions are regressed against the MIR spectra (Fig. S3b).

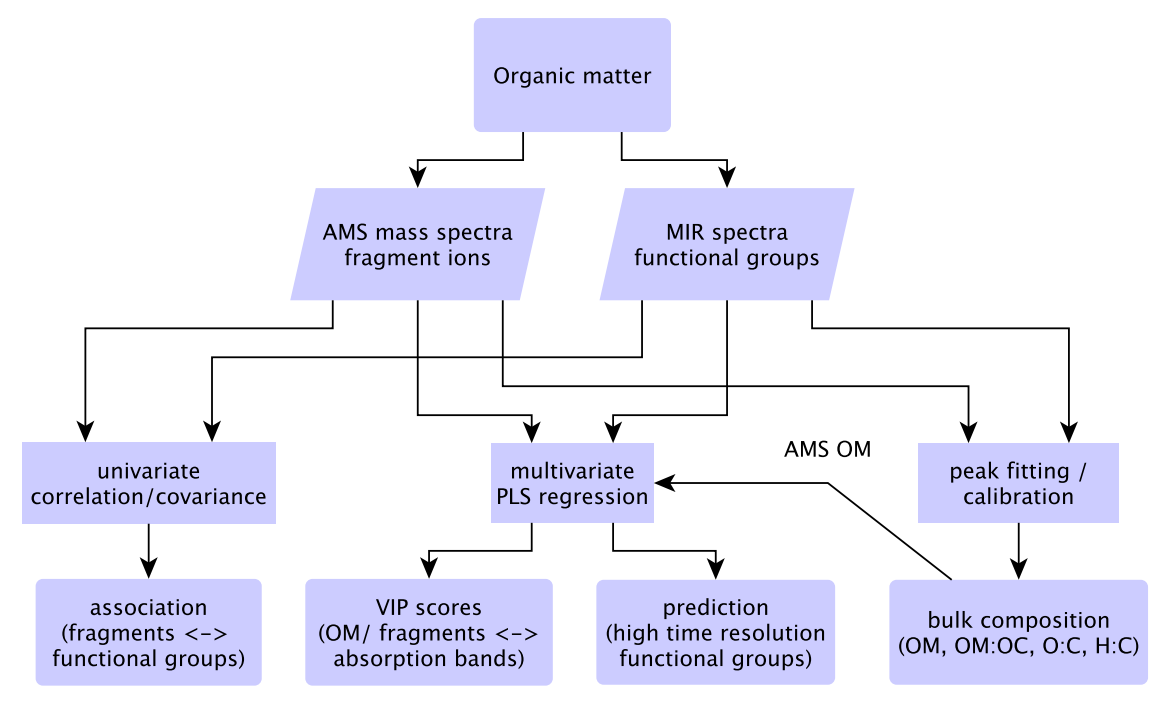

Figure 1. Statistical relations and strategy for comparison of MIR and AMS measurements. The correlation/covariance analysis is performed between AMS mass fragments and MIR functional group abundances from peak fitting. The PLS regression is performed using the AMS total OM or individual fragment concentrations as the independent variable and the MIR absorbance spectra as the dependent variables. 


\subsection{Interpolating FG abundances using AMS mass spectra}

In order to estimate the high-time-resolution FG composition of OM, FG abundances for all filters (normalized by the MIR total OM mass concentration), which were calculated from peak fitting, were regressed against the AMS spectra (normalized by the AMS total OM mass concentration and averaged over the filter sampling periods) using PLSR. A repeated 10-fold cross validation was applied to indicate the optimal number of latent variables. These models were then used to interpolate (hightime-resolution) FG compositions using them AMS spectra and investigate the evolution OM during the course of oxidation when only AMS measurements existed (Fig. S4). Thereafter, the high-resolution O:C ratios separated by FG contribution $\left(\mathrm{O}: \mathrm{C}=\mathrm{O}_{\mathrm{COOH}}: \mathrm{C}_{\text {total }}+\mathrm{O}_{\text {naCO }}: \mathrm{C}_{\text {total }}+\mathrm{O}_{\mathrm{aCOH}}: \mathrm{C}_{\text {total }}\right)$ were calculated from the high-resolution resolution FG compositions following the same approach of Sect. 2.3.1.

\section{Results and discussions}

In the following subsections, bulk OM parameters from AMS and MIR are combined and compared in Sect. 3.1. There after, fragment ion-FG relationships are investigated in Sect. 3.2. Finally, PLSR models are developed to predict FG composition of OM using the AMS mass spectra (Sect. 3.3). Our approach for combining and comparing the AMS and MIR measurements is demonstrated in the diagram of Fig. 1.

\subsection{Combination and comparison of OM measurements}

Influential spectral regions of the MIR spectra and their corresponding FGs are determined for the AMS OM using VIP scores (Sect. 3.1.1). Thereafter, the OM mass concentration, OM:OC, O:C, and H:C ratios calculated using peak fitting to MIR spectra are compared to the average values from AMS for the primary and aged aerosols (Sects. 3.1.2, 3.1.3, and 3.1.4)

\subsubsection{Influential group frequencies for total AMS OM}

VIP scores of the PLSR models regressing MIR absorbances against AMS OM mass concentration highlight certain FGs to be important regarding the OM mass for each fuel burned and aerosol age. As can be seen from Fig. 2, carbonyl $\mathrm{CO}$, aCOH have the highest VIP scores (greater than one) for primary WB aerosols, highlighting their importance in the primary WB OM. The high VIP scores of aCOH is consistent with the fact that $\mathrm{aCOH}$ is a major part of wood constituents. Although $\nu\left(\mathrm{CH}_{2}\right)$ and $\nu\left(\mathrm{CH}_{3}\right)$ (stretching vibrational modes) at $2800-3000 \mathrm{~cm}^{-1}$ do not have high VIP scores for primary WB aerosols, the VIP scores for $\delta\left(\mathrm{CH}_{2}\right)$ at $1470 \mathrm{~cm}^{-1}$ (bending vibrations) are high, suggesting the importance of aCH. The PLSR model probably use the information from the bending peak due to the lower overlap with other bands in the primary WB spectra. The peak around $1600 \mathrm{~cm}^{-1}$ which has a greater-than-one VIP score for primary WB is the result of several overlapping peaks attributed to the organonitrates, aromatic ring $\nu(\mathrm{C}=\mathrm{C})$, amine $\delta(\mathrm{N}-\mathrm{H})$, amide $\delta(\mathrm{N}-\mathrm{H})$, and carboxylate $\nu(\mathrm{C}=\mathrm{O})$ (Pavia et al., 2008). These overlapping absorbances make peak assignment in this region uncertain and complex. However this peak is accompanied by the lignin-related $\nu(\mathrm{C}=\mathrm{C})$ vibrations at $1515 \mathrm{~cm}^{-1}$ (Yazdani et al., 2020b), suggesting the abundance of lignin-like products 
in primary WB OM as also proposed by Bertrand et al. (2018). For the aged WB aerosols, VIP scores are the highest for the broad carboxylic $\nu(\mathrm{OH})$ absorbances at $2400-3400 \mathrm{~cm}^{-1}$ and carbonyl $\nu(\mathrm{CO})$ (acid carbonyl) at $1700 \mathrm{~cm}^{-1}$, suggesting carboxylic acids to be important contributors to the OM mass after SOA formation (Yazdani et al., 2020b). In contrast to the primary WB aerosols, aCOH does not have high VIP scores for the aged WB aerosol (Yazdani et al., 2020b).

For the primary $\mathrm{CC}$ aerosols, $\nu\left(\mathrm{CH}_{2}\right)$ has the highest VIP scores, suggesting the abundance of hydrocarbons likely from volatile compounds of coal. The aromatic ring $\nu(\mathrm{C}=\mathrm{C})$ peak at $1600 \mathrm{~cm}^{-1}$, however, has relatively lower VIP scores, implying that the aromatic rings do not constitute the majority of primary CC OM although coal is mainly composed of highly substituted aromatics. The ammonium $\nu(\mathrm{N}-\mathrm{H})$ peaks at $3200-3400 \mathrm{~cm}^{-1}$ have negative coefficients and high VIP scores, implying that the PLSR model compensates ammonium interference with organics by assigning negative coefficients to the region. For the aged CC aerosols, which are mostly composed of CC SOA, the VIP scores of $\nu\left(\mathrm{CH}_{2}\right)$ are considerably lower. By contrast, carbonyl $\nu(\mathrm{CO})$ and aCOH regions (observed on the shoulder of $\nu(\mathrm{N}-\mathrm{H})$ peaks) have the highest VIP scores, suggesting that CC SOA is mostly composed of carbonyls and alcohols. The out-of plane aromatic $\mathrm{CH}$ band, $\gamma(\mathrm{CH})$, at $750 \mathrm{~cm}^{-1}$, in spite of being visible, does not have high VIP scores in spite of their positive coefficient, suggesting that aromatic $\mathrm{CH}(\mathrm{rCH})$ is not a major part of the aged CC. The $\mathrm{RONO}_{2}$ absorption region at $1630 \mathrm{~cm}^{-1}$ does not have high VIP scores although this region is very prominent in the aerosols aged with the nitrate radical (Yazdani et al., 2020b). This is because the AMS OM concentrations used in this study do not consider the majority organonitrate mass as both $\mathrm{NO}_{2}{ }^{+}$and $\mathrm{NO}^{+}$are attributed to inorganic nitrate. As a result, the organonitrate abundances do not affect the regression models.

In general, the important FGs highlighted by the VIP scores method are the same ones targeted in past studies of atmospheric aerosols (e.g., Ruthenburg et al., 2014; Russell et al., 2009b) and are consistent with our knowledge of POAs and SOAs related to combustion sources (e.g, Bertrand et al., 2018, 2017; Yazdani et al., 2020b). In addition, they provide insight into the fraction of the combusted fuel that is important for OM formation (e.g., hydrocarbons in CC).

\subsubsection{AMS and MIR OM mass concentrations}

It was shown in the last section that four $\mathrm{FGs}, \mathrm{aCH}, \mathrm{COOH}, \mathrm{aCOH}$, and $\mathrm{naCO}$ are the most influential functional groups regarding OM mass. The abundances of the mentioned FGs were estimated using peak fitting to the MIR spectra. The aromatic $\mathrm{C}=\mathrm{C}$ group $(\mathrm{rC}=\mathrm{C}$ ) was not quantified due to the interference with other functional groups and the lack of absorption coefficient data. The peak-fitting results show that the OM concentration estimates from AMS and MIR are highly correlated (Fig. 3a, $R^{2}=0.92$ ). The slope of the MIR OM concentration versus that of AMS (not corrected for collection efficiency) is 1.3. This slope is within the previously reported range (Gilardoni et al., 2009; Russell et al., 2009a, b; Liu et al., 2011) considering collection efficiency of AMS (Yazdani et al., 2020b; Kumar et al., 2018; Canagaratna et al., 2007) and the aerosol volatilization artifacts from PTFE filters (Ruggeri, 2017; Subramanian et al., 2004). Yazdani et al. (2020b) reported the AMS the collection efficiency to range between 0.7 and 1.1 for the same experiments. The OM concentrations estimated by both methods indicate the significant enhancement with aging even without particle and vapor wall loss consideration (on average 2.4 and 2.7 times by AMS and MIR, respectively). The enhancement ratios are in the range of values that were previously reported for SOA formation from logwood stoves (Bertrand et al., 2017; Tiitta et al., 2016; Grieshop et al., 2009; Heringa et al., 2011; Hennigan 


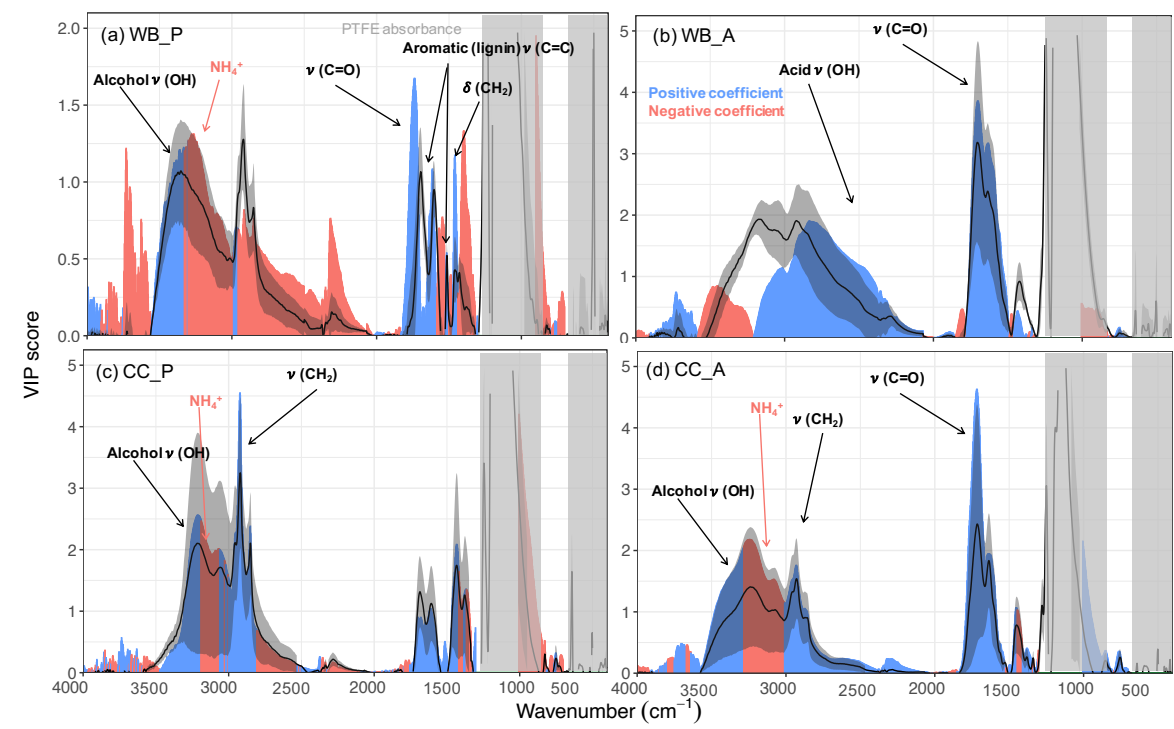

Figure 2. VIP scores of the MIR absorbances regressed against the AMS OM concentration (averaged over the filter sampling periods) for (a) primary wood burning, (b) aged wood burning, (c) primary coal combustion, and (d) aged coal combustion aerosols. Blue/red regions correspond to wavenumbers with positive/negative regression coefficients in the PLSR models, respectively. Solid curves show the average spectrum ( \pm one standard deviation shown by the shaded bands) for each category. Important FGs and their locations are indicated for each category. The PTFE C-F absorption regions are masked by gray rectangles.

et al., 2010). Using different absorption coefficient values for MIR FGs (discussed by Reggente et al., 2019) has little effect on the correlation coefficient.

\subsubsection{AMS and MIR OM:OC ratios}

The OM:OC ratios calculated from the AMS mass spectra were averaged over the filter sampling periods and compared to those measured from peak fitting to MIR spectra. The OM:OC estimates of these two methods agree very well $\left(R^{2}=0.82\right.$ and slope $=0.99$; Fig. 3b) with an average difference of less than 0.15 (Yazdani et al., 2020b). The correlation coefficient of OM:OC ratios is also found to be insensitive to the choice of absorption coefficients reported by Reggente et al. (2019) for MIR spectroscopy. The fact that both methods capture similar OM:OC and mass concentration trends, suggests that a similar fraction of $\mathrm{OM}$ is monitored by both and the uncertainties associated with each method is less than variations due to fuel sources and aging processes. The primary $\mathrm{CC}$ aerosols are estimated to have the lowest OM:OC ratios (1.35-1.5), which is justified by their strong hydrocarbon $(\mathrm{aCH})$ signatures (Fig. 2c). The primary WB samples have slightly higher OM:OC ratios (1.6-1.7 from AMS) primarily due to a relatively higher concentration of aCOH (Fig. 2a). Both instruments estimate that the aged aerosols of the two sources, regardless of the aging method, have higher OM:OC than the primary ones (Fig. 3b). The aged WB aerosols have the highest OM:OC ranging from 1.9 to 2.1 (from AMS), with high concentrations of $\mathrm{COOH}$ (from MIR). The aged CC aerosols have lower average OM:OC ratios compared to the aged WB aerosols, ranging from 1.6 to 1.8. 

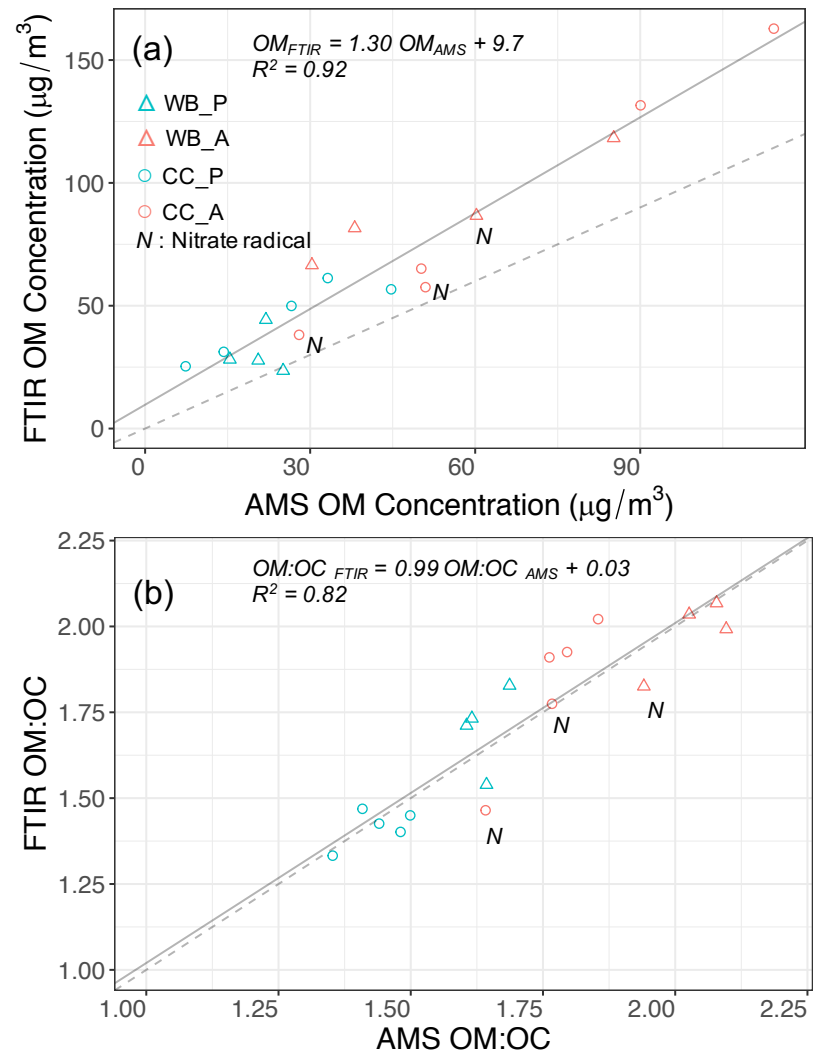

Figure 3. (a) Scatter plot comparing OM concentration estimates by AMS and MIR for primary (P) and aged (A) aerosols of wood burning (WB) and coal combustion (CC) in the environmental chamber experiments. (b) Scatter plot comparing OM:OC estimates from AMS and MIR for primary and aged aerosols in each of the environmental chamber experiments. The fitted and 1:1 lines are solid and dashed, respectively.

For both emission sources, AMS and MIR show that aerosols aged with the hydroxyl radical have higher OM:OC ratios than those aged with the nitrate radical (Fig. 3b). Attributing total AMS nitrate to organics to estimate an upper bound for OM:OC, makes this difference less prominent. However, the nitrate radical only reacts efficiently with certain precursors compared to the hydroxyl radical, resulting in different SOA composition that is reflected in both AMS and MIR measurements.

\subsubsection{AMS and MIR van Krevelen trajectories}

The local slope of the aging trajectory in the van Krevelen diagram is informative about the changes in the functionality of OM (Heald et al., 2010; Ziemann and Atkinson, 2012; Chhabra et al., 2011a), which is also directly measured with MIR spectroscopy. Figure 4 shows the van Krevelen diagram of the WB and CC OM in different experiments. In the WB experiments, AMS oxidation trajectories vary between a straight line and a convex (L-shaped) curve. In the first WB experiment with the hydroxyl radical (WB_OH_1), AMS aging trajectory is almost a straight line implying a monotonic change of FGs during the 
course of aging (Fig. 4a). In the second experiment (WB_OH_2), however, the trajectory is convex with a reduced slope toward the end of aging, implying an increase in the abundance of FGs resulting in a low trajectory slope, e.g. acids (Fig. 4b). This is supported by the high concentration of the $\mathrm{COOH}$ group observed in the MIR spectra of the corresponding aged aerosols (Yazdani et al., 2020b) and will be investigated further in Sect. 3.3. The WB experiment with the nitrate radical (WB_NO3_1) has a slope close to zero with a lower final O:C probably due to the exclusion of the organonitrate group and different SOA formation reactions of the nitrate radical. The relatively low decrease in $\mathrm{H}: \mathrm{C}$ with aging is supported by a relatively lower decrease of aCH absorptions in the MIR spectra of WB aerosols that are aged with the nitrate radical (Yazdani et al., 2020b). The modest decrease in $\mathrm{H}: \mathrm{C}$ with aging is observed to be a characteristic of aging with the nitrate radical regardless of the emission source (Fig. 4d, h, and i), suggesting a more effective $\mathrm{H}$ atom abstraction by $\mathrm{OH}$.

The starting points of the WB oxidation trajectories (from AMS) have $\mathrm{H}: \mathrm{C}$ ratios in the range of 1.6-1.8 and O:C ratios in the range of 0.3-0.4. The ending points have $\mathrm{H}: \mathrm{C}$ ratios in the range 1.4-1.6 and O:C ratios in the range of 0.6-0.7. The observed values are close to that of OA measured by Chhabra et al. (2011a), the OA emissions of logwood combustions by Tiitta et al. (2016), and ambient OA reported by Heald et al. (2010). The average O:C and H:C trends calculated from MIR spectroscopy are generally consistent with that of AMS, showing a decline in $\mathrm{H}: \mathrm{C}$ ratio and increase in O:C ratio. However, there is an offset in the absolute values; in general, $\mathrm{H}: \mathrm{C}$ is estimated to be approximately 0.2 higher by MIR spectroscopy both for the primary and aged WB aerosols.

For the CC experiments, AMS oxidation trajectories usually start at $\mathrm{H}: \mathrm{C}$ ratios around 1.7-1.9 (higher than that of WB supported by the strong aCH signature; Fig. $2 \mathrm{c}$ ) and $\mathrm{O}: \mathrm{C}$ ratios around $0.20-0.25$ and end usually at $\mathrm{H}: \mathrm{C}$ and $\mathrm{O}: \mathrm{C}$ ratios around 1.5-1.7 and 0.35-0.55, respectively. The high $\mathrm{H}: \mathrm{C}$ ratios before aging support the low amount of aromatics to aliphatic $\mathrm{CH}$ observed from MIR spectra. In most of the experiments, a positive curvature in trajectory is observed (Fig. 4e-i), implying a change in the type of FGs produced during the course of aging. The average slopes are close to -1 (from AMS) in the majority of experiments and are slightly higher than those of the WB experiments. The average oxidation slopes that are estimated from MIR spectroscopy are also higher for the CC experiments compared to WB. This observation is supported by the formation of SOAs with higher naCO abundances for CC (Yazdani et al., 2020b), resulting in higher trajectory slopes . However, MIR generally estimates higher O:C (by 0.05-0.1) and lower $\mathrm{H}: \mathrm{C}$ ratios (by approximately 0.2 ) for the aged CC aerosols compared to AMS.

The observed deviations between the two instruments might stem from the low OM mass collected on the filters that increases the baseline correction and peak fitting uncertainties in MIR analysis, in addition to the existence of FGs that are not considered in the peak fitting algorithm (e.g., ethers, PAHs, $\mathrm{rC}=\mathrm{C}$ and $\mathrm{rCH}$ ). Sampling biases of semi-volatile compounds on PTFE filters (Subramanian et al., 2004) and the uncertainties of AMS elemental ratio calibrations (Canagaratna et al., 2015b; Aiken et al., 2008) can also affect the results.

\subsection{AMS fragment ion-MIR FG relationships}

In Sects. 3.2.1 and 3.2.2, the connection between the AMS fragment ions and MIR FGs is investigated using different statistical methods (covariance, correlation, and VIP scores). The combined summary of these analyses is shown in Table 1. 


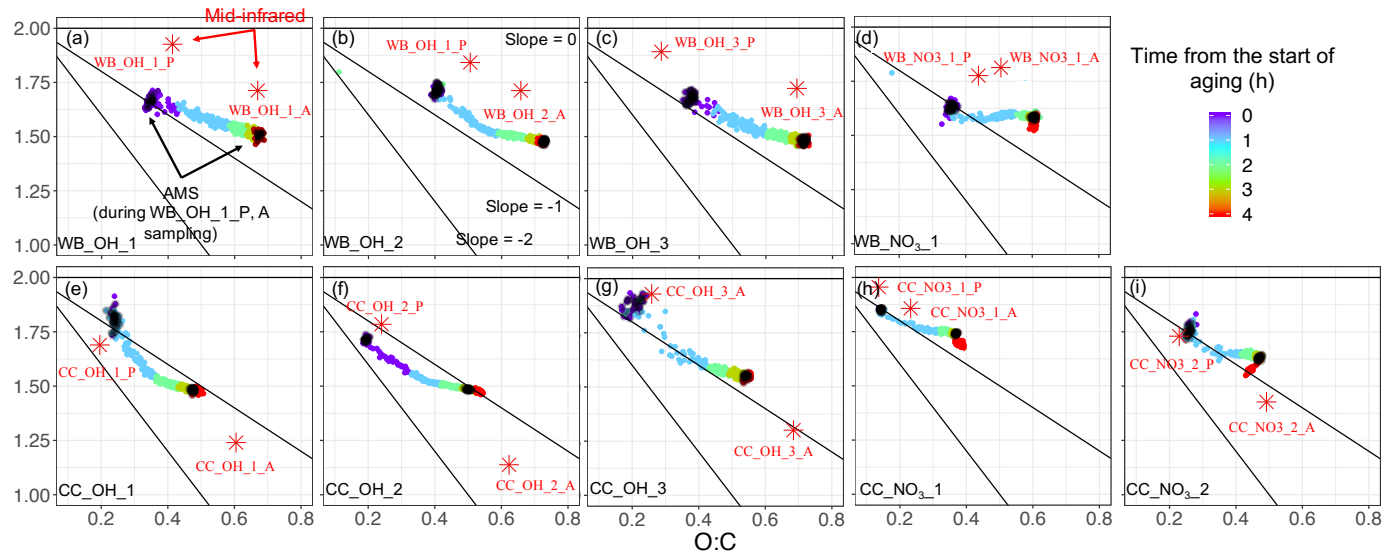

Figure 4. Comparison of AMS van Krevelen (H:C vs O:C) aging trajectories (color circles) for wood burning (WB) and coal combustion (CC) experiments with MIR estimates for aerosols collected on PTFE filters before and after aging (red stars). Black circles in AMS trajectories correspond to the filter sampling periods for the primary and aged aerosols. The filter names are the same as Yazdani et al. (2020b). P: primary, A: aged.

Table 1. Summary of important fragment ions for each functional group based on the analysis method. Important fragments are shown in blue.

\begin{tabular}{|c|c|c|c|c|}
\hline FGs & Covariance & Correlation & VIP scores & $\begin{array}{c}\text { Multivariate } \\
\text { regression } \\
\mathrm{CO}_{2}^{+}, \mathrm{CHO}^{+}, \mathrm{C}_{2} \mathrm{H}_{3} \mathrm{O}^{+} \\
\end{array}$ \\
\hline $\mathbf{a C H}$ & $\begin{array}{l}\mathrm{C}_{x} \mathrm{H}_{2 \mathrm{x} \pm 1}^{+} \text {(e.g. } \\
\left.\mathrm{C}_{3} \mathrm{H}_{7}^{+}, \mathrm{C}_{4} \mathrm{H}_{9}^{+}\right)\end{array}$ & $\begin{array}{l}\mathrm{C}_{x} \mathrm{H}_{\mathrm{Y}}^{+} \text {(e.g., } \mathrm{C}_{3} \mathrm{H}_{5}{ }^{+}, \mathrm{C}_{3} \mathrm{H}_{7}{ }^{+}, \\
\mathrm{C}_{6} \mathrm{H}_{9}^{+}, \mathrm{C}_{8} \mathrm{H}_{9}^{+} \text {, heavy fragments: } \\
\left.\mathrm{C}_{8} \mathrm{H}_{17}^{+}\right)\end{array}$ & $\mathrm{C}_{3} \mathrm{H}_{5}^{+}$ & - \\
\hline $\mathrm{aCOH}$ & $\begin{array}{l}\mathrm{CHO}^{+}, \mathrm{CH}_{3} \mathrm{O}^{+} \\
\mathrm{C}_{2} \mathrm{H}_{4} \mathrm{O}_{2}^{+}\end{array}$ & $\begin{array}{l}\mathrm{C}_{2} \mathrm{H}_{5} \mathrm{O}^{+}, \mathrm{C}_{3} \mathrm{H}_{6} \mathrm{O}_{2}^{+}, \mathrm{C}_{5} \mathrm{H}_{6}^{+} \\
\text {(phenol) }\end{array}$ & $\begin{array}{l}\mathrm{CHO}^{+}, \mathrm{C}_{2} \mathrm{H}_{4} \mathrm{O}_{2}^{+}, \\
\mathrm{C}_{8} \mathrm{H}_{9} \mathrm{O}_{2}^{+}\end{array}$ & $\mathrm{CHO}^{+}, \mathrm{C}_{2} \mathrm{H}_{3} \mathrm{O}^{+}$ \\
\hline $\mathrm{COOH}$ & $\begin{array}{l}\mathrm{CO}_{2}^{+}, \mathrm{CO}^{+}, \mathrm{C}_{2} \mathrm{H}_{3} \mathrm{O}^{+}, \\
\mathrm{CHO}^{+}\end{array}$ & $\begin{array}{l}\mathrm{C}_{x} \mathrm{H}_{y} \mathrm{O}_{>1}^{+} \text {(e.g., } \mathrm{C}_{2} \mathrm{H}_{3} \mathrm{O}_{2}^{+}, \\
\mathrm{C}_{7} \mathrm{H}_{5} \mathrm{O}_{4}^{+} \text {) }\end{array}$ & $\mathrm{CO}_{2}^{+}$ & $\mathrm{CO}_{2}^{+}, \mathrm{CHO}^{+}$ \\
\hline naCO & $\mathrm{CO}_{2}^{+}, \mathrm{CO}^{+}, \mathrm{C}_{2} \mathrm{H}_{3} \mathrm{O}^{+}$ & $\mathrm{C}_{x} \mathrm{H}_{y} \mathrm{O}_{1}{ }^{+}$(e.g., $\left.\mathrm{C}_{7} \mathrm{H}_{4} \mathrm{O}^{+}\right)$ & $\mathrm{C}_{2} \mathrm{H}_{3} \mathrm{O}^{+}$ & $\mathrm{C}_{2} \mathrm{H}_{3} \mathrm{O}^{+}$ \\
\hline $\mathrm{RONO}_{2}$ & - & $\begin{array}{l}\mathrm{C}_{2} \mathrm{H}_{3} \mathrm{O}^{+}, \mathrm{C}_{4} \mathrm{H}_{9} \mathrm{NO}_{3}{ }^{+}, \\
\mathrm{C}_{6} \mathrm{H}_{10} \mathrm{NO}_{2}^{+}\end{array}$ & $\mathrm{CHO}^{+}, \mathrm{C}_{2} \mathrm{H}_{3} \mathrm{O}^{+}$ & - \\
\hline
\end{tabular}




\subsubsection{Correlation and covariance analyses (univariate)}

The aCH group has high covariance with $\mathrm{C}_{x} \mathrm{H}_{2 x-1}$ and $\mathrm{C}_{x} \mathrm{H}_{2 x+1}$ fragments $\left(\mathrm{C}_{3} \mathrm{H}_{5}{ }^{+}, \mathrm{C}_{3} \mathrm{H}_{7}{ }^{+}, \mathrm{C}_{4} \mathrm{H}_{7}{ }^{+}, \mathrm{C}_{4} \mathrm{H}_{9}{ }^{+}\right.$, and $\mathrm{C}_{5} \mathrm{H}_{9}{ }^{+}$; Fig. 5). The highest correlations are between the aCH group and $\mathrm{C}_{3} \mathrm{H}_{5}{ }^{+}, \mathrm{C}_{3} \mathrm{H}_{7}{ }^{+}, \mathrm{C}_{5} \mathrm{H}_{7}{ }^{+}$, and $\mathrm{C}_{6} \mathrm{H}_{9}{ }^{+}$(Fig. 6). The relationship of heavier fragments such as $\mathrm{C}_{7} \mathrm{H}_{13}{ }^{+}$and $\mathrm{C}_{8} \mathrm{H}_{15}{ }^{+}$with aCH is more prominent in the correlation analysis. These fragments are especially abundant in the primary CC aerosols, suggesting these aerosols is composed of relatively longer chain hydrocarbons that even after fragmentation, produce relatively heavy fragments. This observation is also supported by the MIR spectra of these samples, which possess sharp $\mathrm{CH}_{2}$ and weak $\mathrm{CH}_{3}$ peaks (Yazdani et al., 2020b, a). Faber et al. (2017) have previously shown the relation between $\mathrm{C}_{4} \mathrm{H}_{7}{ }^{+}$and $\mathrm{aCH}$. The $\mathrm{m} / \mathrm{z} 57$ signal in the unit-mass-resolution mass spectra (which also includes $\mathrm{C}_{4} \mathrm{H}_{9}{ }^{+}$signal) has been proposed to be a tracer of unburned fuel emissions (Schneider et al., 2006). However, its correlation coefficient with $\mathrm{aCH}$ has been shown to be quite variable and sometimes negative (Russell et al., 2009a). This discrepancy partly stems from the contribution of $\mathrm{C}_{3} \mathrm{H}_{5} \mathrm{O}^{+}$to $\mathrm{m} / \mathrm{z} 57$ (Faber et al., 2017) and partly from the fact that molecules with different chain-lengths, degrees of branching, and heteroatoms produce different and source-dependent fragmentation patterns for $\mathrm{C}_{x} \mathrm{H}_{y}{ }^{+}$. In addition, the existence of several highly correlated ion fragments with aCH in this study suggests the superiority of a multi-variate approach to obtain information about $\mathrm{aCH}$ from the AMS mass spectra.

The $\mathrm{COOH}$ group has the highest covariance with $\mathrm{CO}_{2}{ }^{+}, \mathrm{CO}^{+}, \mathrm{C}_{2} \mathrm{H}_{3} \mathrm{O}^{+}$, and $\mathrm{CHO}^{+}$. Since the $\mathrm{CO}^{+}$concentration is estimated from that of $\mathrm{CO}_{2}{ }^{+}$, the former fragment it not investigated separately. The highest correlations are, on the other hand, with $\mathrm{C}_{2} \mathrm{H}_{3} \mathrm{O}_{2}{ }^{+}$and several heavier fragments with multiple oxygen atoms such as $\mathrm{C}_{7} \mathrm{H}_{5} \mathrm{O}_{4}{ }^{+}$, which are abundant in the aged WB aerosols. The high covariance with the $\mathrm{CO}_{2}{ }^{+}$fragment is supported by the fact that $\mathrm{CO}_{2}{ }^{+}$is produced from the fragmentation of mono- and dicarboxylic acids (Duplissy et al., 2011; Zhang et al., 2005). The heavier fragments with multiple oxygen atoms $\left(\mathrm{C}_{x} \mathrm{H}_{y} \mathrm{O}_{z>1}{ }^{+}\right)$are also indicative of the COOH FG as also reported by Lambe et al. (2012) and might be source-specific as, for example, $\mathrm{C}_{7} \mathrm{H}_{5} \mathrm{O}_{4}{ }^{+}$is only detected in the WB aerosols. In the WB aerosols, the $\mathrm{COOH}$ group is correlated significantly ( $r \sim 0.96$ ) with $\mathrm{CHO}_{2}{ }^{+}$, the fragment known to be produced from the $\alpha$-cleavage of carboxylic acids (Pavia et al., 2008). The $\mathrm{C}_{2} \mathrm{H}_{4} \mathrm{O}_{2}{ }^{+}$fragment is also known to be produced from acids having $\gamma$ hydrogen through McLafferty rearrangement and its concentration increases with the extensive aging for the WB and CC aerosols (Yazdani et al., 2020b). However, the strong interference of levoglucosan fragmentation, abundant in WB emissions, with $\mathrm{C}_{2} \mathrm{H}_{4} \mathrm{O}_{2}{ }^{+}$makes investigation of $\mathrm{COOH}-\mathrm{C}_{2} \mathrm{H}_{4} \mathrm{O}_{2}{ }^{+}$ relation difficult. With the help of MIR, which does not suffer from the same interference, samples with negligible levoglucosan concentrations were separated. For these samples, a fairly strong correlation $(r \sim 0.82)$ between $\mathrm{COOH}$ and $\mathrm{C}_{2} \mathrm{H}_{4} \mathrm{O}_{2}{ }^{+}$was observed.

The aCOH group covaries most significantly with $\mathrm{CHO}^{+}, \mathrm{CH}_{3} \mathrm{O}^{+}, \mathrm{C}_{3} \mathrm{H}_{5} \mathrm{O}^{+}$(which contributes to $\mathrm{m} / \mathrm{z} 57$ in the unit-massresolution spectra), $\mathrm{C}_{2} \mathrm{H}_{3} \mathrm{O}^{+}$, and $\mathrm{C}_{2} \mathrm{H}_{4} \mathrm{O}_{2}{ }^{+}$. The $\mathrm{CHO}^{+}$fragment has been often interpreted as the tracer of esters, polyols and compounds with polyfunctional groups without the carboxylic $\mathrm{COOH}$ (Canagaratna et al., 2015a). This fragment, however, is also known to be produced by aldehydes although the aldehyde $\mathrm{C}-\mathrm{H}$ band is not observed in the MIR spectra of the samples under study. Faber et al. (2017) also showed that the signal ratio of $\mathrm{C}_{2} \mathrm{H}_{3} \mathrm{O}^{+}$to $\mathrm{C}_{4} \mathrm{H}_{7}{ }^{+}$is linearly correlated with the molar ratio of aCOH to $\mathrm{aCH}$. The connection of $\mathrm{C}_{2} \mathrm{H}_{3} \mathrm{O}^{+}$with alcohols, however, should be treated with caution as carbonyls can also 
produce the same mass fragment. The $\mathrm{C}_{2} \mathrm{H}_{4} \mathrm{O}_{2}{ }^{+}$fragment appears to be important for aCOH and has been previously shown to be related to anhydrous sugars in the biomass burning smoke (Schneider et al., 2006). The $\mathrm{CH}_{3} \mathrm{O}^{+}$fragment is produced from the $\alpha$ cleavage of alcohols (Pavia et al., 2008). The highest correlations in this work are, however, between the aCOH group and $\mathrm{C}_{2} \mathrm{H}_{5} \mathrm{O}^{+}$and $\mathrm{C}_{3} \mathrm{H}_{6} \mathrm{O}_{2}{ }^{+}$fragments and some other fragments such as $\mathrm{C}_{5} \mathrm{H}_{6}{ }^{+}$. The $\mathrm{C}_{2} \mathrm{H}_{5} \mathrm{O}^{+}$fragment is known to be produced from the $\alpha$ cleavage of alcohols (Pavia et al., 2008). The $\mathrm{C}_{5} \mathrm{H}_{6}{ }^{+}$fragment, correlated to a lower extent with aCOH, can be produced by phenol fragmentation after loosing CO, which is also abundant in WB emissions (Bruns et al., 2017).

The naCO group covaries most significantly with $\mathrm{CO}^{+}, \mathrm{C}_{2} \mathrm{H}_{3} \mathrm{O}^{+}$, and $\mathrm{CO}_{2}{ }^{+}$. Contrary to $\mathrm{COOH}, \mathrm{CHO}^{+}$appears to have a low covariance with naCO. The $\mathrm{C}_{2} \mathrm{H}_{3} \mathrm{O}^{+}$fragment is known to be produced by aliphatic ketones and aldehydes (Pavia et al., 2008; Eadon et al., 1971). As discussed by Yazdani et al. (2020b), the naCO in the CC samples are believed to be mostly ketone based on their $\mathrm{C}=\mathrm{O}$ frequency. The naCO group is highly correlated with some $\mathrm{C}_{x} \mathrm{H}_{y}{ }^{+}$fragments (e.g., $\mathrm{C}_{4} \mathrm{H}_{3}{ }^{+}, \mathrm{C}_{6} \mathrm{H}_{4}{ }^{+}$) and some single-oxygen fragments (e.g, $\mathrm{C}_{5} \mathrm{HO}^{+}, \mathrm{C}_{7} \mathrm{H}_{4} \mathrm{O}^{+}$, and $\mathrm{C}_{7} \mathrm{H}_{5} \mathrm{O}^{+}$). The $\mathrm{C}_{7} \mathrm{H}_{5} \mathrm{O}^{+}$fragment is known to be produced by aromatic ketones (Pavia et al., 2008) and $\mathrm{C}_{x} \mathrm{H}_{y} \mathrm{O}_{1}{ }^{+}$has been attributed to carbonyls (Lambe et al., 2012). The $\mathrm{C}_{2} \mathrm{H}_{3} \mathrm{O}^{+}: \mathrm{CO}_{2}{ }^{+}$ ratio is relatively higher in samples aged with the nitrate radical or samples that have considerable amounts of the naCO group (Fig. S5), suggesting that $\mathrm{C}_{2} \mathrm{H}_{3} \mathrm{O}^{+}$is produced mainly by molecules possessing naCO or SOAs formed with the nitrate radical.

There are mid-infrared signatures attributed to levoglucosan and lignin that are prominent in the primary WB aerosols and diminish with aging. These signatures are important markers of biomass burning and have been used to identify atmospheric smoke-impacted samples (Yazdani et al., 2020b). Correlation analysis of these features with the AMS ion fragments (Fig. S6) show that the $\mathrm{C}_{8} \mathrm{H}_{9} \mathrm{O}^{+}$fragment is related to lignin. In fact, one might attribute the $\mathrm{m} / \mathrm{z} 121$ fragment to two peaks $\mathrm{C}_{7} \mathrm{H}_{5} \mathrm{O}_{2}{ }^{+}$and $\mathrm{C}_{8} \mathrm{H}_{9} \mathrm{O}^{+}$for hydroxyphenyl $(\mathrm{H})$ lignin and $\mathrm{C}_{4} \mathrm{H}_{9} \mathrm{O}_{2}{ }^{+}$of guaiacyl $(\mathrm{G}$ ) lignin, respectively (Li et al., 2012; Tolbert and Ragauskas, 2017). The $\mathrm{C}_{2} \mathrm{H}_{4} \mathrm{O}_{2}{ }^{+}$and $\mathrm{C}_{3} \mathrm{H}_{5} \mathrm{O}_{2}{ }^{+}$fragments have high correlation with MIR levoglucosan signatures. The fragment at $\mathrm{m} / \mathrm{z}$ 102 , in spite of having generally a low concentration, has the highest correlation with the levoglucosan concentration measured from the MIR spectra. This fragment might be used alternatively in case the interference of other compounds (e.g., acids) for the lighter fragments related to levoglucosan is substantial.

In this work, organonitrates were not quantified. However, the MIR peak attributed to $\mathrm{RONO}_{2}$ has high correlation coefficients with $\mathrm{C}_{2} \mathrm{H}_{3} \mathrm{O}^{+}$and several other oxygenated fragments such as $\mathrm{C}_{4} \mathrm{H}_{7} \mathrm{O}^{+}$. Nitrogenated fragments containing the nitrate and nitro groups such as $\mathrm{C}_{4} \mathrm{H}_{9} \mathrm{NO}_{3}{ }^{+}$and $\mathrm{C}_{6} \mathrm{H}_{10} \mathrm{NO}_{2}{ }^{+}$also appear to have moderate correlation coefficients (approximately 0.6) with the $\mathrm{RONO}_{2}$ peak in the MIR spectrum (Fig. S7) although the quantification of nitrogenated fragments is known to be complicated in the $\mathrm{V}$ mode.

To summarize, the high correlation coefficients of several fragments with each FG suggest that FG information is retained to a good degree in the AMS spectra. We also found that multiple FGs are correlated with each of the major oxygenated fragments, $\left(\mathrm{CO}^{+}, \mathrm{C}_{2} \mathrm{H}_{3} \mathrm{O}^{+}, \mathrm{CO}_{2}{ }^{+}\right.$, and $\left.\mathrm{CHO}^{+}\right)$. As a result, a multivariate approach should be taken to infer $\mathrm{FG}$ abundances from the AMS spectra. 


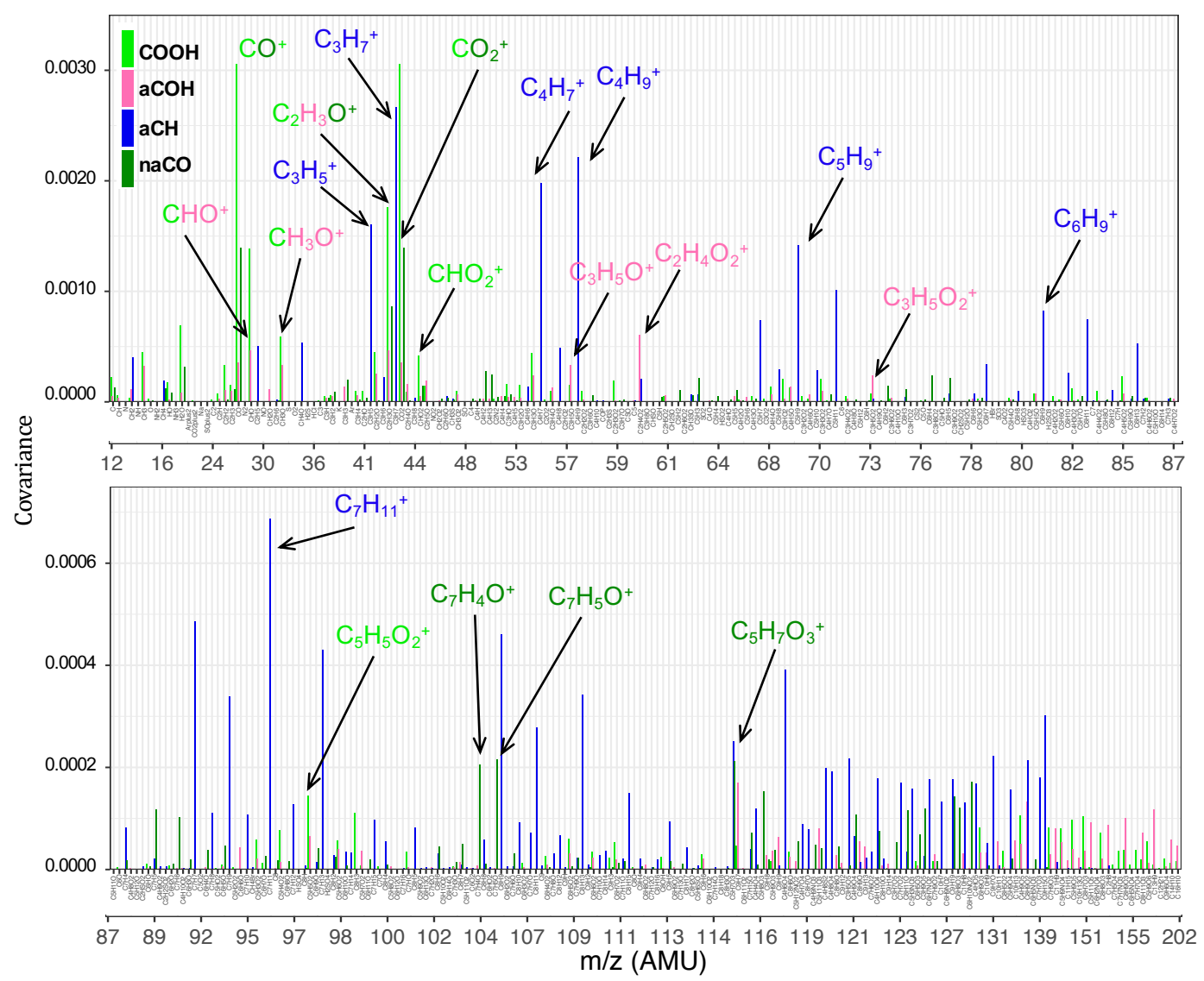

Figure 5. Bar plots showing covariances of normalized AMS fragment ion concentrations and normalized FG abundances. Only positive covariances are shown.

\subsubsection{VIP scores (multivariate)}

As can be seen from Fig. 7, the $\mathrm{CO}_{2}{ }^{+}$fragment has the highest VIP scores for the carbonyl $\nu(\mathrm{CO})$ and broad acid $\nu(\mathrm{OH})$ peaks from 2400 to $3400 \mathrm{~cm}^{-1}$. This is consistent with previous studies (e.g., Zhang et al., 2005) and our univariate analyses (Sect. 3.2.1). On the other hand, the $\nu(\mathrm{CH})$ region (2800 to $3200 \mathrm{~cm}^{-1}$ ), interfering with the broad acid $\mathrm{OH}$ stretching band, has high VIP scores with negative regression coefficient, showing that aCH relative concentration is anti-correlated with $\mathrm{CO}_{2}{ }^{+}$. Although some interference for the $\mathrm{CO}_{2}{ }^{+}$fragment is expected from gas-phase $\mathrm{CO}_{2}$ in the AMS spectra, our results show that the compensation method appears to eliminate this interference effectively.

The $\mathrm{COH}^{+}$has the highest VIP scores for the $\mathrm{RONO}_{2}$ peaks and the broad alcohol $\nu(\mathrm{OH})$ at $3400 \mathrm{~cm}^{-1}$. These results suggest that alcohols and the SOA species produced during the aging with the nitrate radical (that can also be alcohols) are mostly responsible for producing this mass fragment. Although the interference form the gas-phase ${ }^{15} \mathrm{~N}^{14} \mathrm{~N}$ can be significant 


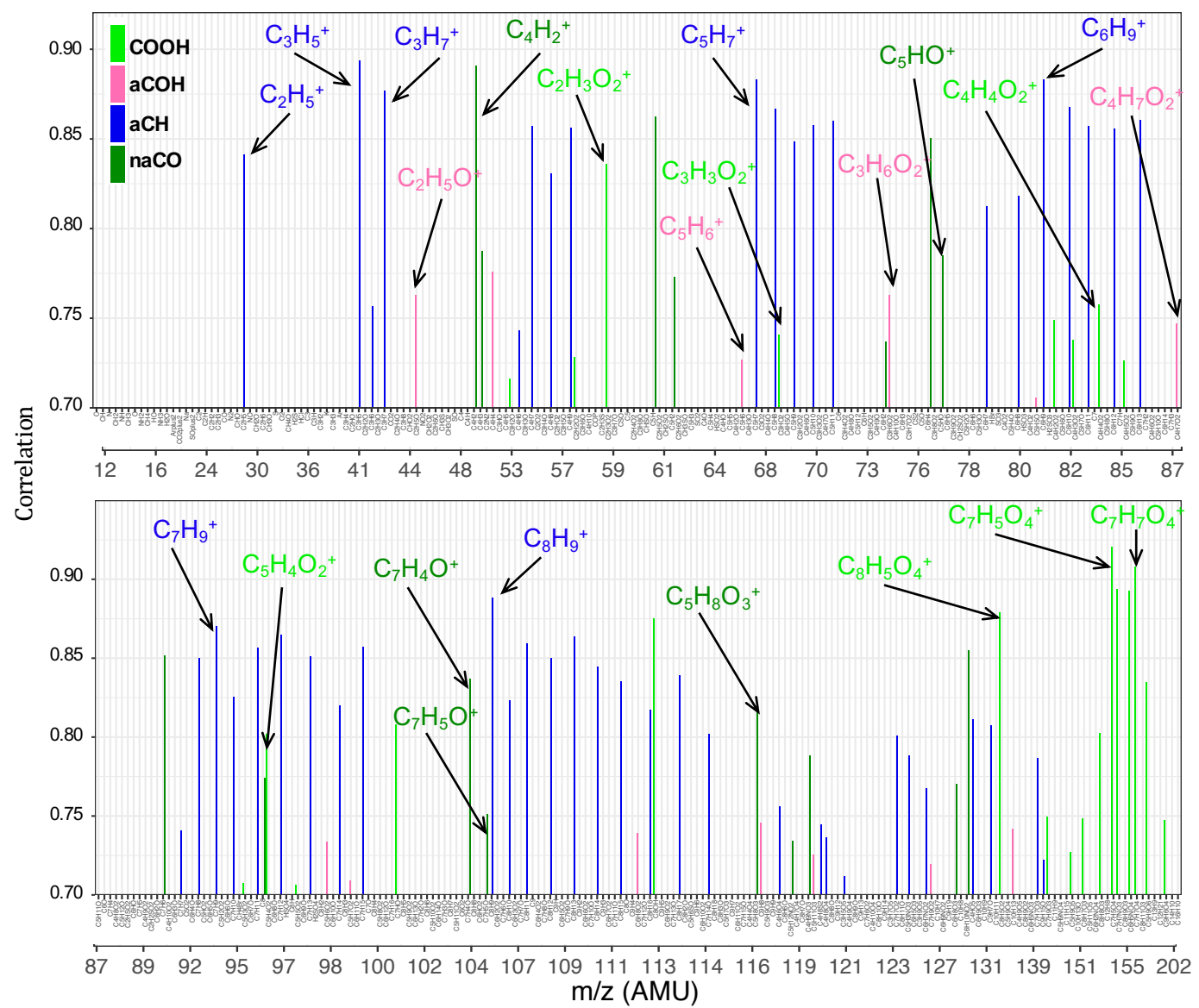

Figure 6. Bar plots showing the Pearson correlation coefficients of normalized individual fragment ion concentrations and normalized FG abundances. Only values $>0.7$ are shown.

for $\mathrm{CHO}^{+}$, our results show that $\mathrm{CHO}^{+}$appears to be meaningfully indicative of alcohols after compensation for the gas-phase interference.

The $\mathrm{C}_{2} \mathrm{H}_{3} \mathrm{O}^{+}$fragment has the highest VIP scores for the carbonyl $\mathrm{CO}$ and the $\mathrm{RONO}_{2}$ peaks and also to a lesser extent for the broad acid $\nu(\mathrm{OH})$ peak. This observation suggests that $\mathrm{C}_{2} \mathrm{H}_{3} \mathrm{O}^{+}$is mostly produced by fragmentation of carbonyls and SOA species formed by aging with the nitrate radical and to a lesser extent carboxylic acids.

The $\mathrm{C}_{3} \mathrm{H}_{5}{ }^{+}$fragment was chosen for the VIP scores analysis due to having high concentrations for both CC and WB aerosols. This fragment has the highest VIP scores with positive regression coefficients for the $\nu(\mathrm{CH})\left(2800-3000 \mathrm{~cm}^{-1}\right)$ and $\delta(\mathrm{CH})$ $\left(1300-1500 \mathrm{~cm}^{-1}\right)$ peaks, showing that this fragment is directly related to $\mathrm{aCH}$ for both sources. This result has been expected but also highlights the fact that $\mathrm{C}_{x} \mathrm{H}_{y}{ }^{+}$fragments should be chosen wisely based on the aerosol source to provide useful information about the aCH group. 


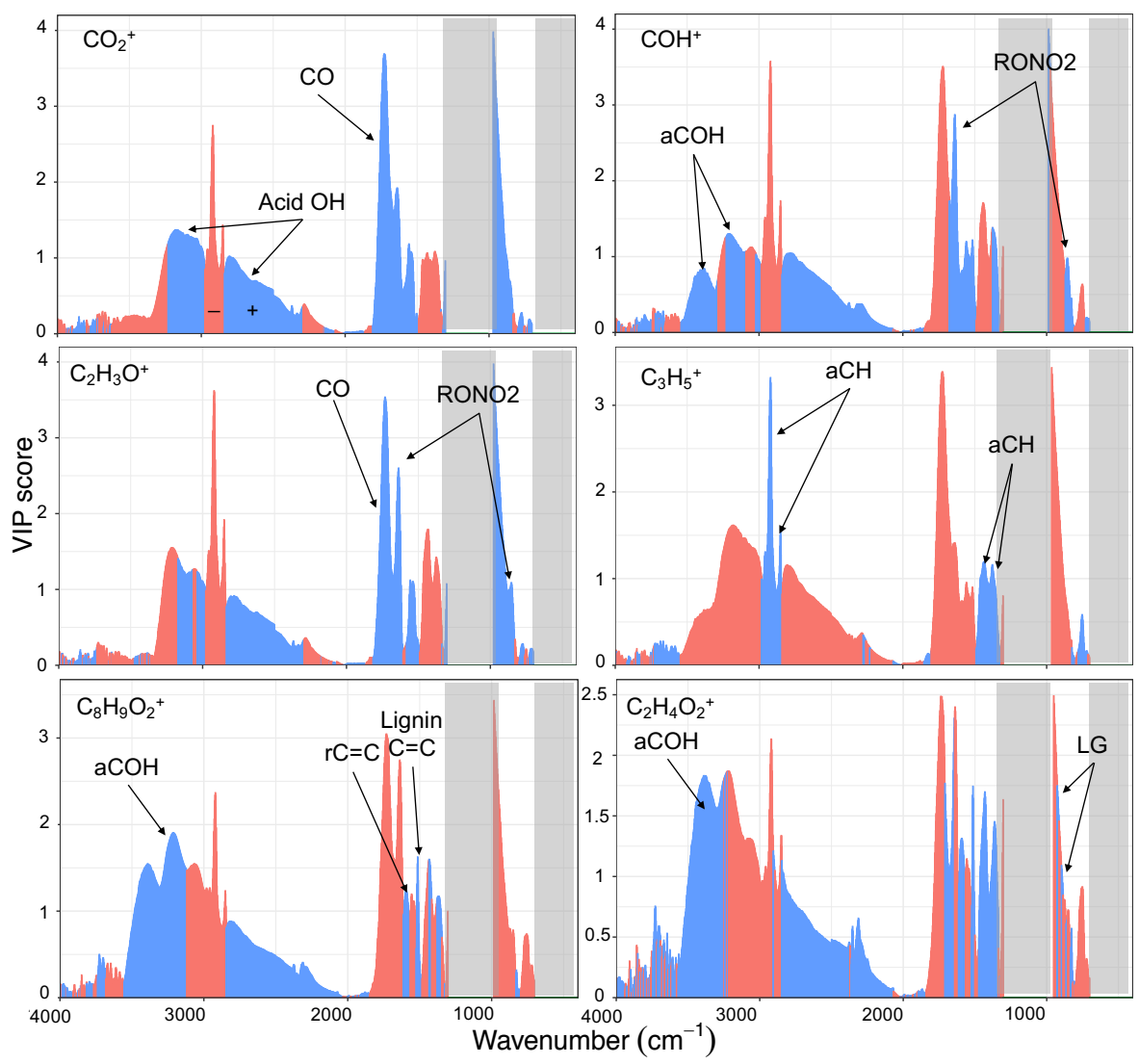

Figure 7. VIP scores of MIR absorbances regressed against AMS fragment ion concentrations (averaged over the filter sampling periods). Blue and red scores correspond to wavenumbers with positive and negative regression coefficients in the PLS models, respectively. Important FGs for each mass fragment are indicated and PTFE absorption regions are masked by gray rectangles.

Regarding the biomass burning markers, the $\mathrm{C}_{8} \mathrm{H}_{9} \mathrm{O}_{2}{ }^{+}$fragment that is proposed to be produced by the fragmentation of lignin molecules (Li et al., 2012; Tolbert and Ragauskas, 2017) has the highest VIP scores with positive coefficients in the aromatic $\nu(\mathrm{C}=\mathrm{C})\left(1515\right.$ and $\left.1600 \mathrm{~cm}^{-1}\right)$ and aCOH regions, suggesting the connection of this fragment with aromatic compounds having a lignin-like substitution that generates the sharp peak at $1515 \mathrm{~cm}^{-1}$ and aCOH groups. The $\mathrm{C}_{2} \mathrm{H}_{4} \mathrm{O}_{2}{ }^{+}$fragment that is proposed to be produced predominantly by fragmentation of levglucosan molecules has the highest VIP scores with positive coefficients in the $\mathrm{aCOH}$ region $\left(3400 \mathrm{~cm}^{-1}\right)$, suggesting the abundance of $\mathrm{aCOH}$ in molecules producing this fragment. In addition, high VIP scores with positive regression coefficients is observed in the $850-1000 \mathrm{~cm}^{-1}$ region, which was previously proposed to be related to levoglucosan fingerprint absorbances (Yazdani et al., 2020b).

We also performed a simple multivariate linear regression between the oxygenated $\mathrm{FGs}(\mathrm{aCOH}$, naCO, and $\mathrm{COOH})$ and major fragments $\left(\mathrm{CO}_{2}^{+}, \mathrm{CHO}^{+}\right.$and $\mathrm{C}_{2} \mathrm{H}_{3} \mathrm{O}^{+}$; Fig S8) for the experiments in which the hydroxyl radical was used as oxidant. As shown in Fig. S8, regressing $\mathrm{CO}_{2}{ }^{+}$against $\mathrm{COOH}, \mathrm{aCOH}$, and naCO results in the highest regression coefficient for the $\mathrm{COOH}$ 
group. In a similar regression for $\mathrm{CHO}^{+}$, the relative contribution of aCOH increases (Fig. S8). However, a high regression coefficient for $\mathrm{COOH}$ is still observed. The regression for $\mathrm{C}_{2} \mathrm{H}_{3} \mathrm{O}^{+}$highlights a relatively greater contribution of naCO (Fig. S8). However, as for $\mathrm{CHO}^{+}$, a high regression coefficient for $\mathrm{COOH}$ is also observed. As summarized in Table 1, different statistical methods suggest that the major fragments are usually produced more by a certain oxygenated FG, while interference from other FGs might also be significant. This motivates the use of multivariate methods for predicting FG abundances using fragment ion concentrations in the following section.

\subsection{MIR FG interpolation using AMS mass spectra}

We showed in previous sections that AMS and MIR measurements are consistent. We also found that FG information is maintained in the AMS mass spectra, which motivated the use of multivariate methods to access this information. For this purpose, normalized AMS spectra were regressed against normalized FG compositions from MIR peak fitting. The fit quality of the developed models is reasonable (Figs. S9 and S10) with their $R^{2}$ ranging from 0.71 to 0.94 . These models use mass fragments to predict the FG compositions that were found to be important in previous sections. We used the developed PLSR models to interpolate the functional group composition of WB and CC OM between the filter sampling periods (primary and aged) using the AMS spectra (Fig. 8). These models are especially helpful as AMS has a considerably better time resolution and can be used to investigate the FG evolution of OM during the course of aging.

The interpolated functional group compositions (Figs. 8, S11, and S12) show different FG compositions and trends during the course of oxidation for WB and CC aerosols. This is predominantly seen in the fraction of oxygenated functional groups that emerge with aging. For the WB experiments, the aCH relative abundance falls steeply as aging with the hydroxyl radical starts (Fig. 8a). This is also observed for aCOH. On the other hand the $\mathrm{COOH}$ relative abundance increases significantly as soon as the aging starts and levels off after two hours of aging. The relative abundance of naCO, however, does not change significantly compared to other FGs for the WB experiment (Fig. 8a). There are slight differences between different experiments of WB aging with the hydroxyl radical (also observed in their van Krevelen trajectory in Fig. 4a-c). For instance, the relatively linear trajectory of the WB_OH_1 experiment (Fig. 8a) is concurrent with monotonic FG composition change (Fig. S11a). On the other hand, the curved van Krevelen trajectories of WB_OH_2 and WB_OH_3 (Fig. S12b-c) correspond to the consumption of naCO produced after the start of aging and the gradual increase of the $\mathrm{COOH}$ relative abundance (Fig. S12b-c). The different SOA species formed by oxidation with hydroxyl and nitrate radicals is also reflected in the evolution of OM FG composition. When aging with the nitrate radical, the decrease in the relative abundance of $\mathrm{aCH}$ is much less prominent after the start of aging compared to aging with the hydroxyl radical (Fig. 8b) although the OM mass enhancement is comparable between the two (Fig. S11a-d). This observation suggests the formation of different SOA species with higher relative abundance of aCH when the nitrate radical is used. This is also supported by the horizontal trajectory in the Van krevelen diagram (no decrease in $\mathrm{H}: \mathrm{C}$ ) (Fig. 4d). No clear difference in the composition of oxygenated FGs (except organonitrate) is observed between aging with the hydroxyl and nitrate radicals. However, when the nitrate radical is used, the O:C ratio increases to lower levels and reaches a plateau faster (Fig. 8e-f; also true for the $\mathrm{CC} \mathrm{OM}$ ). This observation is consistent with the fact that the nitrate radical is produced with a single injection but the hydroxyl radical is generated continuously throughout the aging. It is observed 
that most prominent changes in the FG composition for both oxidants occur in the first hour of aging when the OM mass changes the most (Fig S11), while small changes are observed toward the end of aging. Looking at the absolute abundances of functional groups, we observe that the mass concentrations of all $\mathrm{FGs}$ including $\mathrm{aCH}$ and $\mathrm{aCOH}$ increase during the course of aging (Fig S11) and it is the different rate of their increase that changes their relative abundance as shown in Fig. 8.

We observe for the $\mathrm{CC}$ experiments a different composition of FGs emerging after the start of aging that also evolves differently as aging continues. Like for the WB experiments, the $\mathrm{aCH}$ relative abundance decreases drastically with aging (Fig. 8c), while its absolute concentration increases only slightly with aging (Fig. S11). The decrease in the aCH relative abundance is, however, less prominent when the nitrate radical is used (Fig. 8d) as also supported by the lower decrease in the H:C shown the the Van krevelen plots (Fig. 4h-i). Unlike the WB experiments, the relative abundance of the aCOH group increases slightly with aging when using both oxidants (Fig. 8c-d). The relative abundances of naCO and $\mathrm{COOH}$ show more complex behaviors. The relative abundance of naCO increases sharply and naCO becomes the major FG with the start of aging for both oxidant but decreases slightly after continued aging (Fig. 8c-d). The relative abundance of $\mathrm{COOH}$ decreases initially (Fig. 8c), however, after about one hour into the aging process (earlier with the nitrate radical), when there is no more significant OM enhancement, the $\mathrm{COOH}$ relative abundance starts to increase gradually. This observation is consistent with the ripening phenomenon (Wang et al., 2018) in which the composition of the SOA keeps changing and becomes more oxidized, while the change in OM mass is minimal. This phenomenon is also observed in the L-shaped oxidation trajectories of CC OM in the van Krevelen plot of Figs. $4 \mathrm{e}-\mathrm{i}$ for both oxidants.

To summarize, the interpolated FG compositions are supported by the van Krevelen trajectories, but provide insight into the oxidation pathways that cannot be independently obtained from the van Krevelen plots (e.g., several combinations of FGs can produce similar slopes). For two $\mathrm{CC}$ experiments, negative concentrations of $\mathrm{COOH}$ are predicted (Fig S12e-f). These unphysical values are believed to resulted due to uncertainties of PLSR models and quantification uncertainties for the $\mathrm{COOH}$ group from the MIR peak fitting. The predicted trends, however, are still informative.

\section{Concluding remarks}

The four MIR FGs highlighted by the VIP scores method (i.e., aCH, aCOH, $\mathrm{COOH}$, and naCO) explain the OM mass, OM:OC, $\mathrm{H}: \mathrm{C}$, and $\mathrm{O}: \mathrm{C}$ in good agreement with those of AMS for the WB and $\mathrm{CC}$ aerosols. By using univariate and multivariate methods, we found that several light and heavy (generally source-specific) AMS fragment ions are informative about the FG composition of OM. Our analysis indicates that the fragmentation of OM with different proportions of oxygenated FGs $(\mathrm{COOH}, \mathrm{COH}$, and naCO) in AMS produces different proportions of the major oxygenated fragments (i.e., $\mathrm{CO}_{2}{ }^{+}, \mathrm{CHO}^{+}, \mathrm{C}_{2} \mathrm{H}_{3} \mathrm{O}^{+}$). A multivariate method was used to extract the high-time-resolution FG information from the AMS spectra to better understand the evolution of OM composition with aging. The results suggest the formation of moderately oxygenated FGs (e.g., naCO) soon after the start of aging and their transformation to the more oxygenated FG, $\mathrm{COOH}$, after continued aging. 

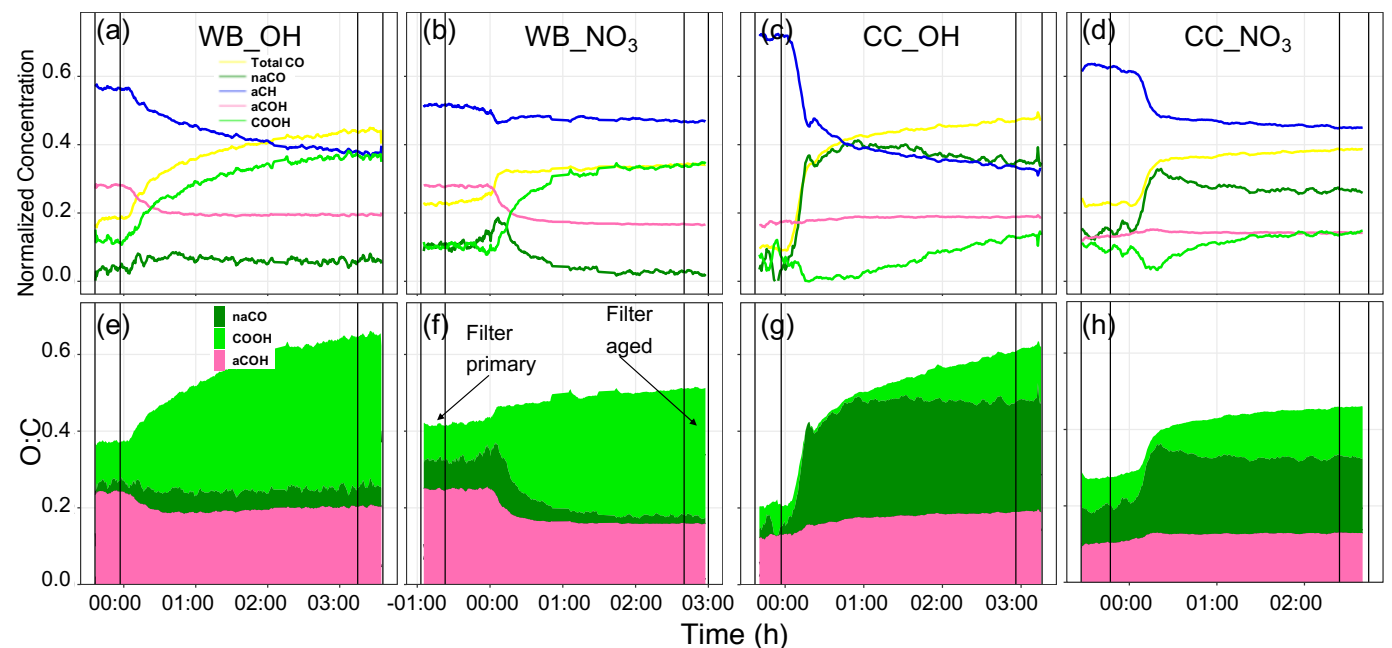

Time (h)

Figure 8. Time series of normalized concentration of functional groups interpolated using AMS mass spectra (a-d) and time series of O:C ratios calculated from the interpolated functional groups $(\mathrm{e}-\mathrm{h})$. An example for each source $(\mathrm{CC}$ and $\mathrm{WB})$ and oxidant $\left(\mathrm{OH}\right.$ and $\left.\mathrm{NO} \mathrm{O}_{3}\right)$ has been shown. The time zero indicates the start of aging (UV lights turned on or oxidant injected). The horizontal lines indicate the periods of filter sampling. 
https://doi.org/10.5194/amt-2021-186

Preprint. Discussion started: 23 July 2021

(c) Author(s) 2021. CC BY 4.0 License.

(c) (1)

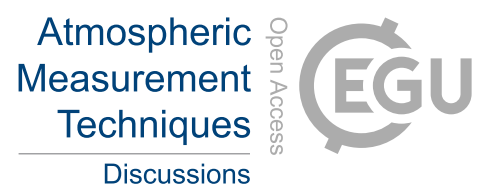

Author contributions. IEH and ST and AY conceived of the project and manuscript. AB and IEH performed the chamber experiments. AB provided AMS spectra. ND prepared and assembled the filter sampling set-up and took their FT-IR spectra. AMD provided atomized compounds and ambient sample spectra. AY wrote the code for data analysis and post processing, performed the data analysis, prepared

475 laboratory standards and analyzed samples, and wrote the manuscript. ST edited the manuscript and provided regular feedback on the analysis. IEH, ASHP, AB, AMD and ND provided input on the analysis and further editing of the manuscript. ST and IEH provided overall supervision of the project.

Competing interests. We declare that no competing interests are present

Acknowledgements. The authors acknowledge funding from the Swiss National Science Foundation (200021_172923 and 200021_169787) and the IMPROVE program (National Park Service cooperative agreement P11AC91045). 


\section{References}

Aiken, A. C., DeCarlo, P. F., Kroll, J. H., Worsnop, D. R., Huffman, J. A., Docherty, K. S., Ulbrich, I. M., Mohr, C., Kimmel, J. R., Sueper, D., Sun, Y., Zhang, Q., Trimborn, A., Northway, M., Ziemann, P. J., Canagaratna, M. R., Onasch, T. B., Alfarra, M. R., Prevot, A. S. H., Dommen, J., Duplissy, J., Metzger, A., Baltensperger, U., and Jimenez, J. L.: O/C and OM/OC Ratios of Primary, Secondary, and Ambient Organic Aerosols with High-Resolution Time-of-Flight Aerosol Mass Spectrometry, Environ. Sci. Technol., 42, 4478-4485, https://doi.org/10.1021/es703009q, 2008.

Barmet, P., Dommen, J., DeCarlo, P. F., Tritscher, T., Praplan, A. P., Platt, S. M., Prévôt, A. S. H., Donahue, N. M., and Baltensperger, U.: OH Clock Determination by Proton Transfer Reaction Mass Spectrometry at an Environmental Chamber, Atmos. Meas. Tech., 5, 647-656, https://doi.org/10.5194/amt-5-647-2012, 2012.

Bertrand, A., Stefenelli, G., Bruns, E. A., Pieber, S. M., Temime-Roussel, B., Slowik, J. G., Prévôt, A. S. H., Wortham, H., El Haddad, I., and Marchand, N.: Primary Emissions and Secondary Aerosol Production Potential from Woodstoves for Residential Heating: Influence of the Stove Technology and Combustion Efficiency, Atmos. Environ., 169, 65-79, https://doi.org/10.1016/j.atmosenv.2017.09.005, 2017.

Bertrand, A., Stefenelli, G., Jen, C. N., Pieber, S. M., Bruns, E. A., Ni, H., Temime-Roussel, B., Slowik, J. G., Goldstein, A. H., Haddad, I. E., Baltensperger, U., Prévôt, A. S. H., Wortham, H., and Marchand, N.: Evolution of the Chemical Fingerprint of Biomass Burning Organic Aerosol during Aging, Atmos. Chem. Phys., 18, 7607-7624, https://doi.org/10.5194/acp-18-7607-2018, 2018.

Boris, A. J., Takahama, S., Weakley, A. T., Debus, B. M., Fredrickson, C. D., Esparza-Sanchez, M., Burki, C., Reggente, M., Shaw, S. L., Edgerton, E. S., and Dillner, A. M.: Quantifying Organic Matter and Functional Groups in Particulate Matter Filter Samples from the Southeastern United States - Part 1: Methods, Atmos. Meas. Tech., 12, 5391-5415, https://doi.org/10.5194/amt-12-5391-2019, 2019.

Bruns, E., Krapf, M., Orasche, J., Huang, Y., Zimmermann, R., Drinovec, L., Močnik, G., El-Haddad, I., G. Slowik, J., Dommen, J., Baltensperger, U., and Prevot, A.: Characterization of Primary and Secondary Wood Combustion Products Generated under Different Burner Loads, Atmos. Chem. Phys., 15, 2825-2841, https://doi.org/10.5194/acp-15-2825-2015, 2015.

Bruns, E. A., Slowik, J. G., Haddad, I. E., Kilic, D., Klein, F., Dommen, J., Temime-Roussel, B., Marchand, N., Baltensperger, U., and Prévôt, A. S. H.: Characterization of Gas-Phase Organics Using Proton Transfer Reaction Time-of-Flight Mass Spectrometry: Fresh and Aged Residential Wood Combustion Emissions, Atmos. Chem. Phys., 17, 705-720, https://doi.org/10.5194/acp-17-705-2017, 2017.

Canagaratna, M. R., Jayne, J. T., Jimenez, J. L., Allan, J. D., Alfarra, M. R., Zhang, Q., Onasch, T. B., Drewnick, F., Coe, H., Middlebrook, A., Delia, A., Williams, L. R., Trimborn, A. M., Northway, M. J., DeCarlo, P. F., Kolb, C. E., Davidovits, P., and Worsnop, D. R.: Chemical and Microphysical Characterization of Ambient Aerosols with the Aerodyne Aerosol Mass Spectrometer, Mass Spectrom. Rev., 26, 185-222, https://doi.org/10.1002/mas.20115, 2007.

Canagaratna, M. R., Jimenez, J. L., Kroll, J. H., Chen, Q., Kessler, S. H., Massoli, P., Hildebrandt Ruiz, L., Fortner, E., Williams, L. R., Wilson, K. R., Surratt, J. D., Donahue, N. M., Jayne, J. T., and Worsnop, D. R.: Elemental Ratio Measurements of Organic Compounds Using Aerosol Mass Spectrometry: Characterization, Improved Calibration, and Implications, Atmos. Chem. Phys., 15, 253-272, https://doi.org/10.5194/acp-15-253-2015, 2015a.

Canagaratna, M. R., Jimenez, J. L., Kroll, J. H., Chen, Q., Kessler, S. H., Massoli, P., Hildebrandt Ruiz, L., Fortner, E., Williams, L. R., Wilson, K. R., Surratt, J. D., Donahue, N. M., Jayne, J. T., and Worsnop, D. R.: Elemental Ratio Measurements of Organic Compounds Using Aerosol Mass Spectrometry: Characterization, Improved Calibration, and Implications, Atmos. Chem. Phys., 15, 253-272, https://doi.org/10.5194/acp-15-253-2015, 2015b. 
https://doi.org/10.5194/amt-2021-186

Preprint. Discussion started: 23 July 2021

(c) Author(s) 2021. CC BY 4.0 License.

Chhabra, P. S., Ng, N. L., Canagaratna, M. R., Corrigan, A. L., Russell, L. M., Worsnop, D. R., Flagan, R. C., and Seinfeld, J. H.: Elemental Composition and Oxidation of Chamber Organic Aerosol, Atmos. Chem. Phys., 11, 8827-8845, https://doi.org/10.5194/acp-11-88272011, 2011a.

Chhabra, P. S., Ng, N. L., Canagaratna, M. R., Corrigan, A. L., Russell, L. M., Worsnop, D. R., Flagan, R. C., and Seinfeld, J. H.: Supplemental Material for Elemental Composition and Oxidation of Chamber Organic Aerosol, Atmos. Chem. Phys., p. 16, https://doi.org/10.5194/acp-11-8827-2011, 2011b.

Chong, I.-G. and Jun, C.-H.: Performance of Some Variable Selection Methods When Multicollinearity Is Present, Chemom. Intell. Lab. Syst., 78, 103-112, https://doi.org/10.1016/j.chemolab.2004.12.011, 2005.

Corrigan, A. L., Russell, L. M., Takahama, S., Äijälä, M., Ehn, M., Junninen, H., Rinne, J., Petäjä, T., Kulmala, M., Vogel, A. L., Hoffmann, T., Ebben, C. J., Geiger, F. M., Chhabra, P., Seinfeld, J. H., Worsnop, D. R., Song, W., Auld, J., and Williams, J.: Biogenic and Biomass Burning Organic Aerosol in a Boreal Forest at Hyytiälä, Finland, during HUMPPA-COPEC 2010, Atmos. Chem. Phys., 13, 12 233-12 256, https://doi.org/10.5194/acp-13-12233-2013, 2013.

DeCarlo, P. F., Kimmel, J. R., Trimborn, A., Northway, M. J., Jayne, J. T., Aiken, A. C., Gonin, M., Fuhrer, K., Horvath, T., Docherty, K. S., Worsnop, D. R., and Jimenez, J. L.: Field-Deployable, High-Resolution, Time-of-Flight Aerosol Mass Spectrometer, Anal. Chem., 78, 8281-8289, https://doi.org/10.1021/ac061249n, 2006.

Duplissy, J., DeCarlo, P. F., Dommen, J., Alfarra, M. R., Metzger, A., Barmpadimos, I., Prevot, A. S. H., Weingartner, E., Tritscher, T., Gysel, M., Aiken, A. C., Jimenez, J. L., Canagaratna, M. R., Worsnop, D. R., Collins, D. R., Tomlinson, J., and Baltensperger, U.: Relating Hygroscopicity and Composition of Organic Aerosol Particulate Matter, Atmos. Chem. Phys., 11, 1155-1165, https://doi.org/10.5194/acp11-1155-2011, 2011.

Eadon, G., Djerassi, C., Beynon, J. H., and Caprioli, R. M.: The Fragmentation of Aliphatic Ketones in the Mass Spectrometer: A Detailed Study of Nonan-4-One Using Ion Kinetic Energy Spectroscopy, Int. J. Mass Spectrom., 5, 917-933, https://doi.org/10.1002/oms.1210050803, 1971.

Faber, P., Drewnick, F., Bierl, R., and Borrmann, S.: Complementary Online Aerosol Mass Spectrometry and Offline FT-IR Spectroscopy Measurements: Prospects and Challenges for the Analysis of Anthropogenic Aerosol Particle Emissions, Atmos. Environ., 166, 92-98, https://doi.org/10.1016/j.atmosenv.2017.07.014, 2017.

Frossard, A. A., Shaw, P. M., Russell, L. M., Kroll, J. H., Canagaratna, M. R., Worsnop, D. R., Quinn, P. K., and Bates, T. S.: Springtime Arctic Haze Contributions of Submicron Organic Particles from European and Asian Combustion Sources, J. Geophys. Res.-Atmos., 116, D05 205, https://doi.org/10.1029/2010JD015178, 2011.

545 Frossard, A. A., Russell, L. M., Massoli, P., Bates, T. S., and Quinn, P. K.: Side-by-Side Comparison of Four Techniques Explains the Apparent Differences in the Organic Composition of Generated and Ambient Marine Aerosol Particles, Aerosol Sci. Tech., 48, v-x, https://doi.org/10.1080/02786826.2013.879979, 2014.

Gilardoni, S., Liu, S., Takahama, S., Russell, L. M., Allan, J. D., Steinbrecher, R., Jimenez, J. L., De Carlo, P. F., Dunlea, E. J., and Baumgardner, D.: Characterization of Organic Ambient Aerosol during MIRAGE 2006 on Three Platforms, Atmos. Chem. Phys., 9, 5417-5432, https://doi.org/10.5194/acp-9-5417-2009, 2009.

Grieshop, A. P., Donahue, N. M., and Robinson, A. L.: Laboratory Investigation of Photochemical Oxidation of Organic Aerosol from Wood Fires 2: Analysis of Aerosol Mass Spectrometer Data, Atmos. Chem. Phys., 9, 2227-2240, https://doi.org/10.5194/acp-9-2227-2009, 2009. 
https://doi.org/10.5194/amt-2021-186

Preprint. Discussion started: 23 July 2021

(C) Author(s) 2021. CC BY 4.0 License.
Atmospheric

Measurement

Techniques

Discussions

Haaland, D. M. and Thomas, E. V.: Partial Least-Squares Methods for Spectral Analyses. 1. Relation to Other Quantitative Calibration

Methods and the Extraction of Qualitative Information, Analytical Chemistry, 60, 1193-1202, https://doi.org/10.1021/ac00162a020, 1988.

Hallquist, M., Wenger, J. C., Baltensperger, U., Rudich, Y., Simpson, D., Claeys, M., Dommen, J., Donahue, N. M., George, C., Goldstein, A. H., Hamilton, J. F., Herrmann, H., Hoffmann, T., Iinuma, Y., Jang, M., Jenkin, M. E., Jimenez, J. L., Kiendler-Scharr, A., Maenhaut, W., McFiggans, G., Mentel, T. F., Monod, A., Prévôt, A. S. H., Seinfeld, J. H., Surratt, J. D., Szmigielski, R., and Wildt, J.: The Formation, Properties and Impact of Secondary Organic Aerosol: Current and Emerging Issues, Atmos. Chem. Phys., 9, 5155-5236, https://doi.org/10.5194/acp-9-5155-2009, 2009.

Hastings, S. H., Watson, A. T., Williams, R. B., and Anderson, J. A.: Determination of Hydrocarbon Functional Groups by Infrared Spectroscopy, Anal. Chem., 24, 612-618, https://doi.org/10.1021/ac60064a002, 1952.

Heald, C. L., Kroll, J. H., Jimenez, J. L., Docherty, K. S., DeCarlo, P. F., Aiken, A. C., Chen, Q., Martin, S. T., Farmer, D. K., and Artaxo, P.: A Simplified Description of the Evolution of Organic Aerosol Composition in the Atmosphere, Geophys. Res. Lett., 37, https://doi.org/10.1029/2010GL042737, 2010.

Helland, I. S.: On the Structure of Partial Least Squares Regression, Communications in Statistics - Simulation and Computation, 17, 581607, https://doi.org/10.1080/03610918808812681, 1988.

Hennigan, C. J., Sullivan, A. P., Collett, J. L., and Robinson, A. L.: Levoglucosan Stability in Biomass Burning Particles Exposed to Hydroxyl Radicals, Geophys. Res. Lett., 37, L09 806, https://doi.org/10.1029/2010GL043088, 2010.

Heringa, M. F., DeCarlo, P. F., Chirico, R., Tritscher, T., Dommen, J., Weingartner, E., Richter, R., Wehrle, G., Prévôt, A. S. H., and Baltensperger, U.: Investigations of Primary and Secondary Particulate Matter of Different Wood Combustion Appliances with a HighResolution Time-of-Flight Aerosol Mass Spectrometer, Atmos. Chem. Phys., 11, 5945-5957, https://doi.org/10.5194/acp-11-5945-2011, 2011.

Iyer, S., Lopez-Hilfiker, F., Lee, B. H., Thornton, J. A., and Kurtén, T.: Modeling the Detection of Organic and Inorganic Compounds Using Iodide-Based Chemical Ionization, J. Phys. Chem. A, 120, 576-587, https://doi.org/10.1021/acs.jpca.5b09837, 2016.

Jathar, S. H., Cappa, C. D., Wexler, A. S., Seinfeld, J. H., and Kleeman, M. J.: Multi-Generational Oxidation Model to Simulate Secondary Organic Aerosol in a 3-D Air Quality Model, Geosci. Model Dev., 8, 2553-2567, https://doi.org/10.5194/gmd-8-2553-2015, 2015.

Kumar, N. K., Corbin, J. C., Bruns, E. A., Massabó, D., Slowik, J. G., Drinovec, L., Močnik, G., Prati, P., Vlachou, A., Baltensperger, U., Gysel, M., El-Haddad, I., and Prévôt, A. S. H.: Production of Particulate Brown Carbon during Atmospheric Aging of Residential Wood-Burning Emissions, Atmos. Chem. Phys., 18, 17 843-17 861, https://doi.org/10.5194/acp-18-17843-2018, 2018.

Kuzmiakova, A., Dillner, A. M., and Takahama, S.: An Automated Baseline Correction Protocol for Infrared Spectra of Atmospheric Aerosols Collected on Polytetrafluoroethylene (Teflon) Filters, Atmos. Meas. Tech., 9, 2615-2631, https://doi.org/10.5194/amt-9-2615-2016, 2016.

Lambe, A. T., Onasch, T. B., Croasdale, D. R., Wright, J. P., Martin, A. T., Franklin, J. P., Massoli, P., Kroll, J. H., Canagaratna, M. R., Brune, W. H., Worsnop, D. R., and Davidovits, P.: Transitions from Functionalization to Fragmentation Reactions of Laboratory Secondary Organic Aerosol (SOA) Generated from the OH Oxidation of Alkane Precursors, Environ. Sci. Technol., 46, 5430-5437, https://doi.org/10.1021/es300274t, 2012.

Li, Y. J., Yeung, J. W. T., Leung, T. P. I., Lau, A. P. S., and Chan, C. K.: Characterization of Organic Particles from Incense Burning Using an Aerodyne High-Resolution Time-of-Flight Aerosol Mass Spectrometer, Aerosol Sci. Tech., 46, 654-665, https://doi.org/10.1080/02786826.2011.653017, 2012.

590 Liu, S., Day, D. A., Shields, J. E., and Russell, L. M.: Ozone-Driven Daytime Formation of Secondary Organic Aerosol Containing Carboxylic Acid Groups and Alkane Groups, Atmos. Chem. Phys., 11, 8321-8341, https://doi.org/10.5194/acp-11-8321-2011, 2011. 
https://doi.org/10.5194/amt-2021-186

Preprint. Discussion started: 23 July 2021

(C) Author(s) 2021. CC BY 4.0 License.
Atmospheric

Measurement

Techniques

Discussions

Liu, S., Ahlm, L., Day, D. A., Russell, L. M., Zhao, Y., Gentner, D. R., Weber, R. J., Goldstein, A. H., Jaoui, M., Offenberg, J. H., Kleindienst,

T. E., Rubitschun, C., Surratt, J. D., Sheesley, R. J., and Scheller, S.: Secondary Organic Aerosol Formation from Fossil Fuel Sources Contribute Majority of Summertime Organic Mass at Bakersfield, J. Geophys. Res.-Atmos., 117, https://doi.org/10.1029/2012JD018170, 2012.

Lopez-Hilfiker, F. D., Pospisilova, V., Huang, W., Kalberer, M., Mohr, C., Stefenelli, G., Thornton, J. A., Baltensperger, U., Prevot, A. S. H., and Slowik, J. G.: An Extractive Electrospray Ionization Time-of-Flight Mass Spectrometer (EESI-TOF) for Online Measurement of Atmospheric Aerosol Particles, Atmos. Meas. Tech., 12, 4867-4886, https://doi.org/10.5194/amt-12-4867-2019, 2019.

Maria, S. F., Russell, L. M., Turpin, B. J., and Porcja, R. J.: FTIR Measurements of Functional Groups and Organic Mass in Aerosol Samples over the Caribbean, Atmos. Environ., 36, 5185-5196, https://doi.org/10.1016/S1352-2310(02)00654-4, 2002.

Nozière, B., Kalberer, M., Claeys, M., Allan, J., D’Anna, B., Decesari, S., Finessi, E., Glasius, M., Grgić, I., Hamilton, J. F., Hoffmann, T., Iinuma, Y., Jaoui, M., Kahnt, A., Kampf, C. J., Kourtchev, I., Maenhaut, W., Marsden, N., Saarikoski, S., Schnelle-Kreis, J., Surratt, J. D., Szidat, S., Szmigielski, R., and Wisthaler, A.: The Molecular Identification of Organic Compounds in the Atmosphere: State of the Art and Challenges, Chem. Rev., 115, 3919-3983, https://doi.org/10.1021/cr5003485, 2015.

Parks, D. A., Griffiths, P. R., Weakley, A. T., and Miller, A. L.: Quantifying Elemental and Organic Carbon in Diesel Particulate Matter by Mid-Infrared Spectrometry, Aerosol Sci. Tech., 0, 1-14, https://doi.org/10.1080/02786826.2021.1917764, 2021.

Pavia, D. L., Lampman, G. M., Kriz, G. S., and Vyvyan, J. A.: Introduction to Spectroscopy, Brooks Cole, Belmont, CA, fourth edn., 2008.

Reggente, M., Dillner, A. M., and Takahama, S.: Analysis of Functional Groups in Atmospheric Aerosols by Infrared Spectroscopy: Systematic Intercomparison of Calibration Methods for US Measurement Network Samples, Atmos. Meas. Tech., 12, 2287-2312, https://doi.org/10.5194/amt-12-2287-2019, 2019.

Ruggeri, G.: On the Functional Group Composition of Organic Aerosol, Ph.D. thesis, Ecole Polytechnique Federale de Lausanne Lausanne (EPFL), https://doi.org/10.5075/epfl-thesis-7578, 2017.

Russell, L. M.: Aerosol Organic-Mass-to-Organic-Carbon Ratio Measurements, Environ. Sci. Technol., 37, 2982-2987, https://doi.org/10.1021/es026123w, 2003.

Russell, L. M., Bahadur, R., Hawkins, L. N., Allan, J., Baumgardner, D., Quinn, P. K., and Bates, T. S.: Organic Aerosol Characterization by Complementary Measurements of Chemical Bonds and Molecular Fragments, Atmos. Environ., 43, 6100-6105, https://doi.org/10.1016/j.atmosenv.2009.09.036, 2009a.

Russell, L. M., Takahama, S., Liu, S., Hawkins, L. N., Covert, D. S., Quinn, P. K., and Bates, T. S.: Oxygenated Fraction and Mass of Organic Aerosol from Direct Emission and Atmospheric Processing Measured on the R/V Ronald Brown during TEXAQS/GoMACCS 2006, J. Geophys. Res.-Atmos., 114, D00F05, https://doi.org/10.1029/2008JD011275, 2009b.

Ruthenburg, T. C., Perlin, P. C., Liu, V., McDade, C. E., and Dillner, A. M.: Determination of Organic Matter and Organic Matter to Organic Carbon Ratios by Infrared Spectroscopy with Application to Selected Sites in the IMPROVE Network, Atmos. Environ., 86, 47-57, https://doi.org/10.1016/j.atmosenv.2013.12.034, 2014.

Schneider, J., Weimer, S., Drewnick, F., Borrmann, S., Helas, G., Gwaze, P., Schmid, O., Andreae, M. O., and Kirchner, U.: Mass Spectrometric Analysis and Aerodynamic Properties of Various Types of Combustion-Related Aerosol Particles, Int. J. Mass Spectrom., 258, 37-49, https://doi.org/10.1016/j.ijms.2006.07.008, 2006.

Shiraiwa, M., Ueda, K., Pozzer, A., Lammel, G., Kampf, C. J., Fushimi, A., Enami, S., Arangio, A. M., Fröhlich-Nowoisky, J., Fujitani, Y., Furuyama, A., Lakey, P. S. J., Lelieveld, J., Lucas, K., Morino, Y., Pöschl, U., Takahama, S., Takami, A., Tong, H., Weber, 
B., Yoshino, A., and Sato, K.: Aerosol Health Effects from Molecular to Global Scales, Environ. Sci. Technol., 51, 13 545-13 567, https://doi.org/10.1021/acs.est.7b04417, 2017.

Subramanian, R., Khlystov, A. Y., Cabada, J. C., and Robinson, A. L.: Positive and Negative Artifacts in Particulate Organic Carbon Measurements with Denuded and Undenuded Sampler Configurations Special Issue of Aerosol Science and Technology on Findings from the Fine Particulate Matter Supersites Program, Aerosol Sci. Tech., 38, 27-48, https://doi.org/10.1080/02786820390229354, 2004.

Takahama, S., Johnson, A., and Russell, L. M.: Quantification of Carboxylic and Carbonyl Functional Groups in Organic Aerosol Infrared Absorbance Spectra, Aerosol Sci. Tech., 47, 310-325, https://doi.org/10.1080/02786826.2012.752065, 2013.

Takahama, S., Ruggeri, G., and Dillner, A. M.: Analysis of Functional Groups in Atmospheric Aerosols by Infrared Spectroscopy: Sparse Methods for Statistical Selection of Relevant Absorption Bands, Atmos. Meas. Tech., 9, 3429-3454, https://doi.org/10.5194/amt-9-34292016, 2016.

Tiitta, P., Leskinen, A., Hao, L., Yli-Pirilä, P., Kortelainen, M., Grigonyte, J., Tissari, J., Lamberg, H., Hartikainen, A., Kuuspalo, K., Kortelainen, A.-M., Virtanen, A., Lehtinen, K. E. J., Komppula, M., Pieber, S., Prévôt, A. S. H., Onasch, T. B., Worsnop, D. R., Czech, H., Zimmermann, R., Jokiniemi, J., and Sippula, O.: Transformation of Logwood Combustion Emissions in a Smog Chamber: Formation of Secondary Organic Aerosol and Changes in the Primary Organic Aerosol upon Daytime and Nighttime Aging, Atmos. Chem. Phys., 16, 13 251-13 269, https://doi.org/10.5194/acp-16-13251-2016, 2016.

Tolbert, A. and Ragauskas, A. J.: Advances in Understanding the Surface Chemistry of Lignocellulosic Biomass via Time-of-Flight Secondary Ion Mass Spectrometry, Energy Sci. Eng., 5, 5-20, https://doi.org/10.1002/ese3.144, 2017.

Turpin, B. J. and Lim, H.-J.: Species Contributions to PM2.5 Mass Concentrations: Revisiting Common Assumptions for Estimating Organic Mass, Aerosol Sci. Tech., 35, 602-610, https://doi.org/10.1080/02786820119445, 2001.

Volkamer, R., Jimenez, J. L., Martini, F. S., Dzepina, K., Zhang, Q., Salcedo, D., Molina, L. T., Worsnop, D. R., and Molina, M. J.: Secondary Organic Aerosol Formation from Anthropogenic Air Pollution: Rapid and Higher than Expected, Geophys. Res. Lett., 33, https://doi.org/10.1029/2006GL026899, 2006.

Wang, N., Kostenidou, E., Donahue, N. M., and Pandis, S. N.: Multi-Generation Chemical Aging of $\alpha$-Pinene Ozonolysis Products by Reactions with OH, Atmos. Chem. Phys., 18, 3589-3601, https://doi.org/10.5194/acp-18-3589-2018, 2018.

Wold, S., Martens, H., and Wold, H.: The Multivariate Calibration Problem in Chemistry Solved by the PLS Method, in: Matrix Pencils, edited by Kågström, B. and Ruhe, A., Lect. Notes Math., pp. 286-293, Springer Berlin Heidelberg, 1983.

655 Wold, S., Johansson, E., and Cocchi, M.: 3D QSAR in Drug Design: Theory, Methods and Applications, ESCOM, Leiden, Holland, pp. 523-550, 1993.

Xu, W., Lambe, A., Silva, P., Hu, W., Onasch, T., Williams, L., Croteau, P., Zhang, X., Renbaum-Wolff, L., Fortner, E., Jimenez, J. L., Jayne, J., Worsnop, D., and Canagaratna, M.: Laboratory Evaluation of Species-Dependent Relative Ionization Efficiencies in the Aerodyne Aerosol Mass Spectrometer, Aerosol Sci. Tech., 52, 626-641, https://doi.org/10.1080/02786826.2018.1439570, 2018.

Yazdani, A., Dillner, A. M., and Takahama, S.: Estimating Mean Molecular Weight, Carbon Number, and OM/OC with MidInfrared Spectroscopy in Organic Particulate Matter Samples from a Monitoring Network, Atmos. Meas. Tech. Discuss., pp. 1-32, https://doi.org/10.5194/amt-2020-79, 2020a.

Yazdani, A., Dudani, N., Takahama, S., Bertrand, A., Prévôt, A. S. H., El Haddad, I., and Dillner, A. M.: Characterization of Primary and Aged Wood Burning and Coal Combustion Organic Aerosols in Environmental Chamber and Its Implications for Atmospheric Aerosols, Atmospheric Chemistry and Physics Discussions, pp. 1-32, https://doi.org/10.5194/acp-2020-924, 2020 b. 
https://doi.org/10.5194/amt-2021-186

Preprint. Discussion started: 23 July 2021

(c) Author(s) 2021. CC BY 4.0 License.

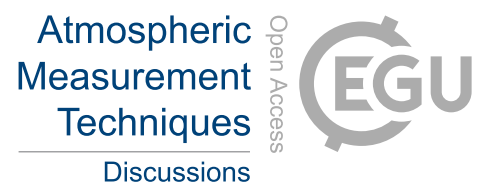

Zahardis, J., Geddes, S., and Petrucci, G. A.: Improved Understanding of Atmospheric Organic Aerosols via Innovations in Soft Ionization Aerosol Mass Spectrometry, Anal. Chem., 83, 2409-2415, https://doi.org/10.1021/ac102737k, 2011.

Zhang, Q., Worsnop, D. R., Canagaratna, M. R., and Jimenez, J. L.: Hydrocarbon-like and Oxygenated Organic Aerosols in Pittsburgh: Insights into Sources and Processes of Organic Aerosols, Atmos. Chem. Phys., 5, 3289-3311, https://doi.org/10.5194/acp-5-3289-2005, 2005.

Zhang, Q., Jimenez, J. L., Canagaratna, M. R., Ulbrich, I. M., Ng, N. L., Worsnop, D. R., and Sun, Y.: Understanding Atmospheric Organic Aerosols via Factor Analysis of Aerosol Mass Spectrometry: A Review, Anal. Bioanal. Chem., 401, 3045-3067, https://doi.org/10.1007/s00216-011-5355-y, 2011.

Ziemann, P. J. and Atkinson, R.: Kinetics, Products, and Mechanisms of Secondary Organic Aerosol Formation, Chem. Soc. Rev., 41, 675 6582-6605, https://doi.org/10.1039/C2CS35122F, 2012. 